\title{
De los números a las personas. Los habitantes de San Vicente (Buenos Aires) según el Primer Censo Nacional Argentino $(1869)^{*}$
}

\author{
por \\ Claudia Contente ${ }^{1}$ \\ Universitat Pompeu Fabra (GRIMSE)
}

Las cédulas censales del Primer Censo Nacional (1869) del partido de San Vicente (Buenos Aires) nos permitirán abordar diversos aspectos de la población, las actividades productivas y su evolución desde principios del siglo. Analizaremos estos aspectos según diversos parámetros como el lugar de residencia (rural o urbano), el género o el lugar de origen de sus habitantes. Más allá de los aspectos puramente cuantitativos, los niveles de ilegitimidad o de alfabetización, así como el tipo de casas y las zonas de residencia, nos permitirán percibir el fundamento de algunos aspectos culturales vigentes aún en la actualidad, completando así una imagen más precisa de esta zona de la campaña en estos tiempos en que los inmigrantes comenzaban a llegar masivamente.

Palabras ClaVE: historia rural; campaña de Buenos Aires; censos; migración; siglo XIX.

Cómo Citar este artículo / Citation: Contente, Claudia, "De los números a las personas. Los habitantes de San Vicente (Buenos Aires) según el Primer Censo Nacional Argentino (1869)", Revista de Indias, LXXVII/269 (Madrid, 2017): 197-234, doi:10.3989/revindias.2017.007.

* Este artículo ha sido elaborado en el marco del proyecto "Dentro y fuera: Cambio institucional e integración social y cultural en el imperio español moderno y contemporáneo, 1550-1950 (una perspectiva comparada de larga duración)", financiado por el Ministerio de Economía y Competitividad (FEDER/MINECO), Ref., HAR2015-68183-P; el proyecto de investigación "La deuda exterior como mecanismo de transformación política social y cultural: el mundo ibérico y el mediterráneo oriental, 1814-1914" financiado por el Ministerio de Economía y Competitividad (FEDER/MINECO) y el proyecto 2014 SGR 1193, financiado por la Agència de Gestió d'Ajuts Universitaris i de Recerca (AGAUR).

1 claudia.contente@upf.edu ORCID iD: http://orcid.org/0000-0001-6424-0108.

Agradezco a María Cristina Cacopardo, José Luis Moreno y a los evaluadores anónimos los comentarios y sugerencias. 
Hacia fines de la década de 1870 la Argentina, recientemente unificada tras largos años de guerras y conflictos, se afirmaba en los mercados internacionales como proveedora de productos agrícolas. Mientras tanto el estado procuraba atraer migrantes que poblaran y contribuyeran al enriquecimiento y bienestar de la nación. Es en ese contexto que entre el 15 y 17 de Septiembre de 1869 tuvo lugar el primer censo nacional ${ }^{2}$, en pleno proceso de construcción y consolidación del Estado, cuando se intentaba de paso «inventar» una nación que diera coherencia al conjunto ${ }^{3}$. Tratándose de crear un sentimiento de identidad nacional, la operación de relevar un censo es de suma utilidad. Entre las múltiples ventajas, la más obvia es conocer mejor la población y su distribución sobre ese vasto territorio que se intentaba controlar, incluido el fenómeno migratorio que se consideraba prioritario fomentar ${ }^{4}$. Al mismo tiempo, la operación censal en sí contribuía sutilmente a la construcción de una noción de pertenencia nacional. Conscientes de todos estos aspectos, el censo fue pensado y confeccionado con sumo cuidado ${ }^{5}$. Varios estudios han explorado ya a través del análisis de las cédulas censales de 1869 diversos aspectos como la composición familiar, los cambios inducidos por la migración europea en las estructuras familiares o el impacto y consecuencias que representó para las familias, tanto del interior argentino como de la zona del litoral, la afluencia migratoria hacia esta última que, en pleno auge económico, ofrecía mejores oportunidades ${ }^{6}$.

En este trabajo nos vamos a apoyar en este censo, más precisamente en las cédulas censales, para estudiar el perfil de San Vicente, sus habitantes y actividades. Se trata de una perspectiva macro, que abarca al conjunto de los residentes, incluyendo a los sectores subalternos que, al habernos legado pocos rastros escritos, suelen escapar a la mirada de los historiadores. Es una visión amplia que se vería claramente enriquecida por el estudio de aspectos concretos a partir de otras fuentes que permitan un enfoque cualitativo y complementario.

Situado a unos $50 \mathrm{~km}$ al sur de la ciudad de Buenos Aires, San Vicente fue, desde sus orígenes, un pago agropecuario rural. Al promediar el siglo XIX,

2 Primer Censo de la República Argentina, 1872.

3 Existe abundante bibliografía a propósito de este tema, ver por ejemplo Chiaramonte, 1997. Garavaglia, 2007.

4 Otero, 1998.

5 Respecto a las circunstancias, debates y otros aspectos que dieron lugar a la concepción de este censo y en sentido más amplio a los orígenes de la estadística en Argentina, consultar Otero, 2006.

6 Por ejemplo, Cacopardo, 1997. Cacopardo y Moreno, 1997. Ratto y Santilli, 2004. Banzato, 2005. 
ya se había afianzado en su especialización en la producción de lana, aunque sin abandonar el ganado vacuno y los cereales que se cultivaban allí desde que se poblara la región?.

Se suele considerar que San Vicente fue fundada en 1780, fecha en la que comienzan los registros parroquiales, aunque se sabe que ya vivían «cristianos» en la zona desde hacía varias décadas. Originariamente el pago de San Vicente cubría una zona amplia con límites poco precisos y, hasta 1822, con una superficie aproximada de unos $8.000 \mathrm{~km}^{2}$. La división administrativa de la campaña bonaerense se fue organizando con el correr de los años y se crearon varios partidos a su costa, en 1869 su jurisdicción se había acotado a unos $1.200 \mathrm{~km}^{2} 8$. A lo largo de ese medio siglo, mientras su espacio administrativo se iba recortando, la población creció muy rápidamente, en 1815 vivían allí 4.376 habitantes, mientras que en 1869 eran 4.249 almas las que poblaban el pago ${ }^{9}$. Los mencionados cambios en la superficie de la jurisdicción vuelven muy poco fiable la estimación de la tasa de crecimiento, a título indicativo diremos que para el conjunto de la campaña de Buenos Aires habría sido del 3,8\% anual en el lapso $1815-1869^{10}$. Esta es una pauta muy general ya que, más allá del proceso de expansión del territorio durante ese período, como es de imaginar, no todas las áreas geográficas conocieron el mismo dinamismo en sus trayectorias ${ }^{11}$.

La llegada de migrantes a Buenos Aires estaba lejos de ser algo nuevo, el desarrollo sostenido de las actividades agrícolas había atraído corrientes migratorias desde su fundación a fines del siglo XVIII. Ya desde entonces, fueron los propios pobladores, a menudo llegados de diversos horizontes quienes contribuyeron a colonizar la región empujando la frontera con los indios ${ }^{12}$. Hasta principios del siglo XIX estos migrantes provenían esencialmente de otras regiones del virreinato, luego esta corriente fue progresivamente rem2012.

7 A propósito de la evolución productiva en ese período ver Míguez, 2008. Hora, 2010;

8 Epifanio, 2001. Registro Estadístico de la Provincia de Buenos Aires, 1869. A propósito de la población y orientación productiva de San Vicente en sus orígenes ver, Contente, 2015.

9 Si en 1815 la población de San Vicente representaba un $10 \%$ de la población total de la campaña bonaerense, 54 años después apenas llegaba al 1,4\% del conjunto.

10 Al pasar de unos 42.800 habitantes en 1815 a 317.000 en 1869.

11 Mateo, 2013. Gelman y Santilli, 2011.

12 Para una visión general de la población de la campaña de Buenos Aires y su evolución a lo largo del siglo XIX véase Mateo, 2013. En cuanto a frontera indígena y el proceso de colonización consultar los trabajos de Ratto, 2003; 2013. Ortelli, 2012. 
plazada por otra de origen europeo que pasó a predominar ampliamente sobre la tradicional «micro migración» regional ${ }^{13}$.

Como decíamos, la provincia de Buenos Aires se benefició particularmente con esta próspera coyuntura económica que requería abundante mano de obra y la convirtió en un destino atractivo para los nuevos pobladores. Si los datos generales del censo mencionan, para el conjunto de la provincia de Buenos Aires, que los migrantes eran un $19,2 \%$ de la población ${ }^{14}$, en San Vicente representaban un $24,7 \%$ de los habitantes. A partir de 1865 San Vicente quedó ligada a Buenos Aires gracias al ferrocarril que iba a Chascomús. Si bien no se han hecho aún estudios a propósito del impacto económico que representó la llegada del tren, se puede intuir fácilmente la importancia de este evento y las perspectivas que abría para la economía local.

En ese entonces, la ganadería lanar prevalecía ampliamente sobre la tradicional ganadería bovina y se había impuesto, incluso, como el primer rubro de exportación ${ }^{15}$. Esta producción se desarrolló a través de una combinación de formas productivas que incluían la estancia y la microempresa familiar. La producción agrícola no había desaparecido pero aún tenía como meta principal los mercados locales e interiores ${ }^{16}$.

Los censos anteriores en la zona habían tenido lugar en los años 1813$1815^{17}$, organizados por la joven administración revolucionaria tras la ruptura con España, según los métodos de la administración colonial y con fines presumiblemente militares: se buscaba estimar la población para evaluar la cantidad de hombres que se podría enrolar para las guerras de independen-

13 Actualmente se considera que el largo ciclo de migraciones europeas comenzó, si bien tímidamente, hacia 1830, alcanzando el máximo afluente migratorio a fines del siglo XIX. Ceva, 2012.

$1490 \%$ eran europeos, entre ellos, una tercera parte eran italianos seguidos de españoles y franceses. Primer Censo de la República Argentina, 1872: 38-45. Massé, 2012.

15 Todavía estaba lejos de ser una gran proveedora de productos agrícolas, recién a partir de 1880 los cereales ocuparían el primer puesto en las exportaciones. Míguez, 2008. Hora, 2010; 2012:145-181. Sábato, 1989.

16 No obstante, se pueden distinguir dos evoluciones diferentes: la zona al norte del Salado que se volcó fuertemente a la producción ovina y el resto de la provincia con un desarrollo basado en la ganadería vacuna y sectores agrícolas que se vieron favorecidos con la llegada del ferrocarril y la consolidación de la frontera, Gelman y Barsky, 2001. Respecto a la evolución del perfil productivo global y de las otras zonas de la campaña bonaerense consultar Gelman y Santilli, 2011.

17 Hubieron igualmente censos en la campaña bonaerense en 1836 y 1838 . Se trata de listas de jefes de familia o de explotaciones con el número de ocupantes que no nos permiten conocer la composición de la unidad. A propósito de estos censos en San Vicente, Contente, 2015. 


\section{Mapa 1. Provincia de Buenos Aires (1865)}

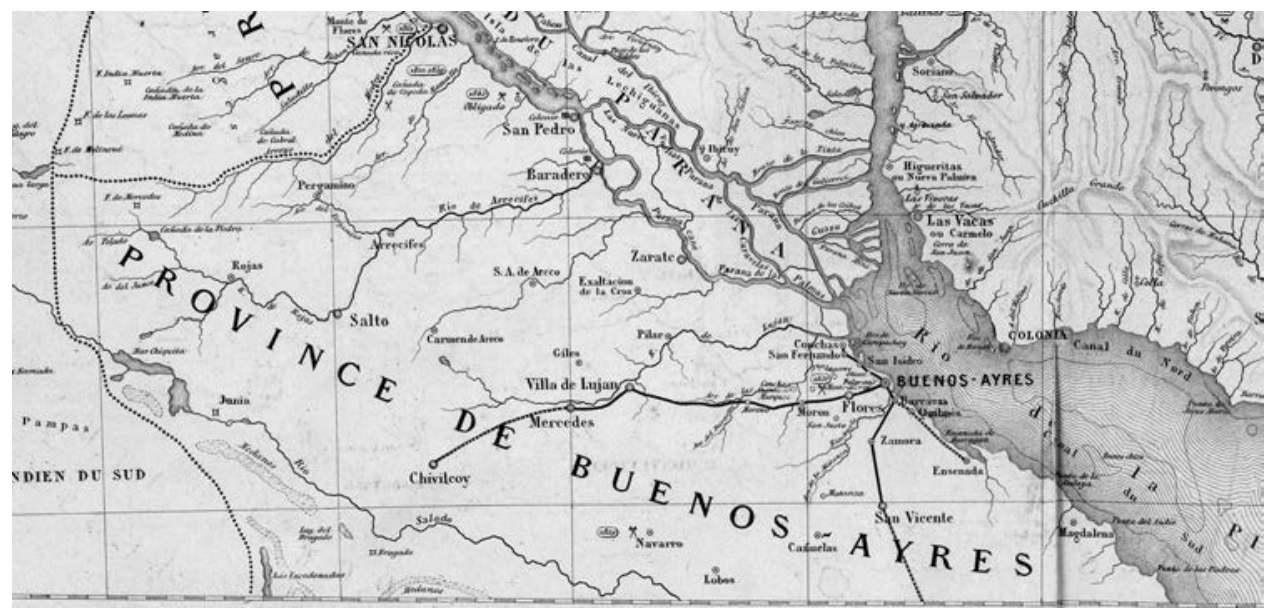

Fuente: Description géographique et statistique de la Conféderation Argentine par V. Martin de Moussy. Deuxième édition atlas, Paris, Librairie de Firmin Didot Frères, Fils et Cie. Imprimeurs de l'Institut, 1873, Planche VIII.

cia $^{18}$. Se considera que el censo de 1869 fue el que inauguró la etapa propiamente estadística en Argentina: contrariamente a las experiencias anteriores, un equipo de especialistas elaboró un cuestionario preciso, buscando respuestas concretas a problemáticas bien definidas ${ }^{19}$.

Contiene la información básica de todo censo como nombre, apellido, edad, sexo, profesión, lugar de origen. Pero más allá de estos datos habituales, los representantes del Estado se interesaron también por otros aspectos tales como el nivel de alfabetización, la ilegitimidad o la eventual invalidez de los habitantes. Hay sin embargo una diferencia estructural importante con respecto a los censos anteriores, el de 1869 está compuesto por listas de nombres en las cuales muy raramente se puede diferenciar los grupos domésticos ${ }^{20}$. Esto se debe, probablemente, a que quienes concibieron la matriz del censo no veían la nación como un conjunto de grupos familiares sino más bien como

18 Algunos autores consideran que los censos de 1813-1815 podrían haber tenido igualmente fines electorales, buscando evaluar la cantidad de representantes que cada región debería enviar a la Asamblea, ver GIHRR, 2004.

19 Otero, 2006.

$20 \mathrm{Al}$ menos en los libretos de Buenos Aires, los del interior separan más frecuentemente los grupos domésticos. 
una suma de individuos ${ }^{21}$. Es quizás igualmente por esa razón, porque se pretendía ver a través de las actividades profesionales lo que cada persona podía aportar al enriquecimiento de la nación que, contrariamente a los censos precedentes, en 1869 se registran, por ejemplo, las actividades femeninas. Aunque en la publicación sólo se ofrecen los datos de las ocupaciones sin discriminar por sexo.

\section{San Vicente a través de sus números. Los habitantes}

El censo está compuesto por 26 cuadernos confeccionados por 17 censistas: 22 de zonas rurales, tres " urbanos » y uno de la Estación Doncelaar donde vive un grupo familiar de 9 personas y que aquí, por razones prácticas, hemos incluido en el pueblo, aunque en ese entonces, Donceelaar todavía no fuese un pueblo propiamente dicho.

Un detalle a tener en cuenta es que originalmente el pueblo estaba situado en una zona de difícil acceso y que se solía inundar, por ese motivo hacia 1856-57 y tras largos años de discusiones, fue trasladado a donde se encuentra en la actualidad ${ }^{22}$. De modo que en 1869 el pueblo llevaba unos 13 años de existencia, lo que sin duda está relacionado con la extremadamente baja proporción de población urbana en comparación con otros partidos de la provincia $^{23}$.

Algunas pautas nos ayudan a situarnos en el partido, sabemos que los 4.249 habitantes estaban distribuidos en unas 750 casas... que eran en su gran mayoría de paja (84\%), solo unas pocas eran de «azotea», como se llamaba a las casas de material (11\%) y eran aún menos frecuentes las de madera (5\%).

La pirámide general tiene el aspecto habitual de una población «joven y en crecimiento», según la fórmula que se emplea habitualmente en estos casos: los niños y jóvenes de 1 a 20 años representan más del $50 \%$ de los habitantes.

Vivían en el pago bastante más hombres (2.325) que mujeres (1.924). Como se sabe, las actividades agrícolas requerían abundante mano de obra y esto se traducía en una importante presencia de migrantes. Los provenientes

\footnotetext{
21 Otero, 2006.

22 El pueblo había estado anteriormente por la zona donde hoy en día se encuentra el cementerio. Epifanio, 2001.

23 Mientras en San Vicente se declara que un 13,5\% de la población vive en el pueblo, en una zona cercana como Chascomús por ejemplo, es un $34,4 \%$ de los residentes que se encuentran instalados en zona urbana (Gelman y Santilli, 2011). En otros pagos más alejados como Mercedes, esta proporción puede alcanzar el 50\% (Barcos, 2013).
} 


\section{Gráfico 1. SAN Vicente 1869-Población General}

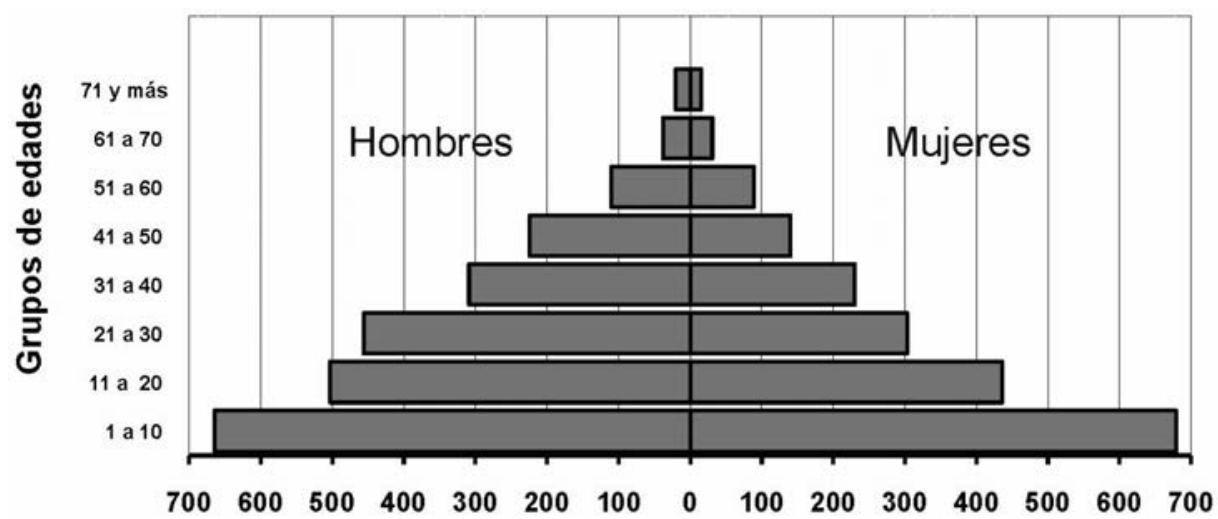

de otras provincias de la Argentina eran relativamente poco numerosos, un $3,5 \%{ }^{24}$ mientras que los de origen europeo constituían la gran mayoría y, como es de suponer, predominaban entre ellos los hombres solteros ${ }^{25}$. Esto distorsionaba seriamente el «mercado matrimonial» local. De hecho, mientras prácticamente la mitad de los hombres mayores de 21 años eran solteros (47\%), entre las mujeres esta proporción pasaba a algo más de una sobre cuatro $(26 \%)$ $y$, obviamente, se volvía difícil encontrar esposa en el lugar ${ }^{26}$.

Hay otro aspecto importante que queda disimulado cuando observamos la pirámide general de población, separar argentinos de extranjeros nos dará algunas pistas:

Entre los argentinos hay un importante vacío en la población masculina a partir de los 15 y hasta los 50 años aproximadamente, lo que coincide exactamente con las edades en que hay más trabajadores migrantes presentes.

No hay que olvidar que los años precedentes habían conocido cruentos conflictos y que la guerra del Paraguay tenía lugar precisamente en ese mo-

${ }^{24}$ El 94,8\% de los argentinos son originarios de Buenos Aires, el 3,5\% del interior y no se señala el origen para $1,7 \%$ de los argentinos censados.

25 Relación de masculinidad general en San Vicente: 120 hombres por 100 mujeres. Por grupos de edad es de 98 entre 1 y 10 años, 115 entre 11 y 20, para alcanzar 144 entre 21 y 60 años.

A propósito del celibato definitivo masculino estimado a partir del estado civil en Tandil ver Otero, 1995.

26 Es abundante la bibliografía a propósito de la inserción de los migrantes por el matrimonio, consultar al respecto Otero, 2006: 142-149. Míguez, Argeri, Bjerg y Otero, 1991. Otero y Pellegrino, 2004. Contente, 2014. 
Gráfico 2. San Vicente, 1869. Solteros (20 a 59 AÑos) POR SeXo

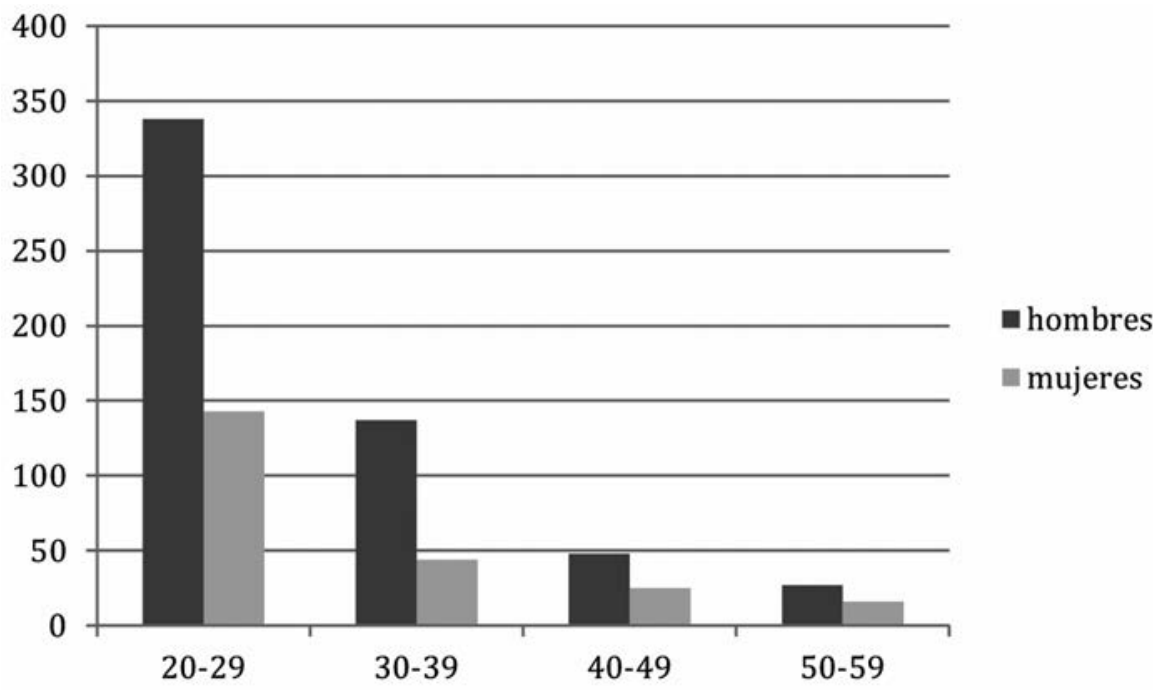

Gráfico 3. San Vicente, 1869. Población POR EDAD, SEXo y ORIGen ARGENTINOS Y EXTRANJEROS, SAN VICENTE 1869

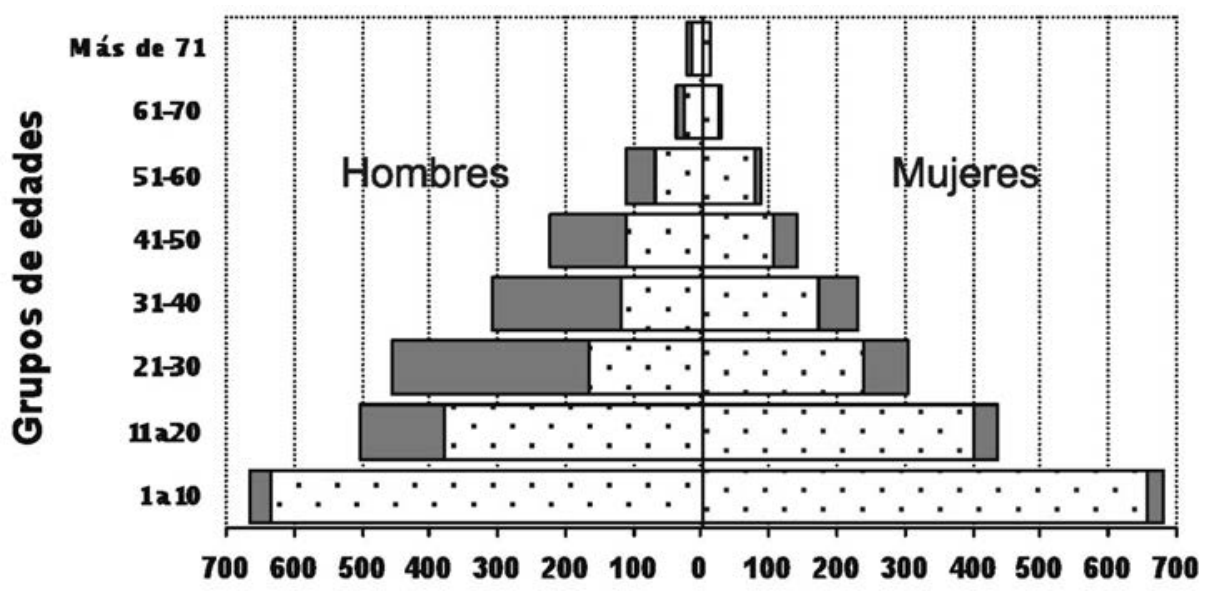

口extranjeros $\square$ argentinos 
mento: buena parte de esos hombres argentinos que faltan entre los pobladores nativos han fallecido en esas contiendas o se encuentran movilizados en la guerra del Paraguay ${ }^{27}$.

Muchos de ellos pueden encontrarse igualmente en otras zonas a la búsqueda de mejores oportunidades ${ }^{28}$. Los inmigrantes extranjeros que, como se recordará, estaban eximidos del servicio militar, están entonces cubriendo holgadamente la ausencia de los hombres argentinos lo que, sin duda, facilitará la instalación e inserción para aquellos que decidan quedarse.

\section{El ESPACIO Y LAS VIVIENDAS}

El censo incluye al final de cada libreta un resumen de la cantidad de habitantes, familias y casas especificando el tipo de construcción, lo que nos permite observar otros aspectos generales. Lo primero que salta a la vista es que mientras las argentinos parecen preferir la zona rural, una proporción considerable de los migrantes se concentraban en el pueblo y el ejido (cuartel 1). Es precisamente en estas zonas donde había mayor cantidad de casas de «azotea» (de material) y de madera: es en el pueblo y en el ejido donde justamente residen la mayor parte de los artesanos, como albañiles y carpinteros que disponen del savoir faire indispensable para construírsela y que son, en gran mayoría, extranjeros. Es obvio que algunas familias rurales o de comerciantes acomodados ${ }^{29}$ podían permitirse construir una casa de material.

En cuanto a la zona rural, los cuarteles 2 y 4 son los que sugieren mayor bienestar, es allí donde hay mayor proporción de casas de «azotea», las familias son más numerosas y viven más personas por casa: son las familias suficientemente ricas y bien instaladas que suelen albergar más miembros en su seno $^{30}$. El cuartel 2 es la zona más cercana a la ciudad de Buenos Aires, - coincidía al menos parcialmente con el actual Burzaco- allí vivían familias instaladas desde hacía largo tiempo en la zona y abundan las casas de «azotea». Conocemos por otras fuentes la descripción de algunas casas ubicadas en el cuartel 2 como la de Blas Ortega ${ }^{31}$, una casa de material de 30 varas de largo

27 Se designan como huérfanos de padre a un $9 \%$ de los niños menores de 12 años, $7,6 \%$ son huérfanos de madre y $2 \%$ de padre y madre.

28 Cacopardo y Moreno, 1997.

29 Por ejemplo los de la Rosa, familia de estancieros, cuya casa está ubicada en el centro de San Vicente y se conserva en la actualidad.

30 García González, 2011. Dubert, 2008.

31 Archivo Civil y Comercial del Departamento Judicial de 1ra Instancia en los Civil de la Provincia de Buenos Aires, La Plata, Suc. Ortega Blas, 1873, leg. 80, paralizado 1932. 


\section{Cuadro 1. San Vicente 1869. Distribución Geográfica DE LA POBLACIÓN SEGÚN EL ORIGEN*}

\begin{tabular}{|c|c|c|c|c|c|c|}
\cline { 2 - 5 } \multicolumn{1}{c|}{} & \multicolumn{2}{c|}{ Argentinos } & \multicolumn{2}{c|}{ Extranjeros } & \multicolumn{1}{c|}{} \\
\hline Cuartel & Cantidad & $\mathbf{\%}$ & Cantidad & \% & Total & \% \\
\hline 2 & 738 & 76,5 & 227 & 23,5 & 965 & 22,7 \\
\hline 3 & 544 & 73,3 & 198 & 26,7 & 742 & 17,5 \\
\hline 4 & 463 & 75,2 & 153 & 24,8 & 616 & 14,5 \\
\hline 5 & 720 & 88,1 & 97 & 11,9 & 817 & 19,2 \\
\hline Total rural & 2.465 & 78,2 & 675 & 21,5 & 3.140 & 73,9 \\
\hline 1 (ejido) & 387 & 72 & 150 & 27,9 & 537 & 12,6 \\
\hline pueblo & 345 & 60,31 & 227 & 39,68 & 572 & 13,5 \\
\hline Total & 3.197 & 75,2 & 1.052 & 24,8 & 4.249 & 100 \\
\hline
\end{tabular}

* Incluidas las libretas 3 y 23.

\section{Cuadro 2. San Vicente, 1869, Distribución de las CaSas en los DIFERENTES CUARTELES*}

\begin{tabular}{|c|c|c|c|c|c|c|c|c|c|c|c|c|c|c|}
\hline \multirow[t]{2}{*}{ Casas } & \multicolumn{2}{|c|}{ Pueblo } & \multicolumn{2}{|c|}{$\begin{array}{c}\text { Cuartel } 1 \\
\text { (ejido) }\end{array}$} & \multicolumn{2}{|c|}{$\begin{array}{c}\text { Cuartel } 2 \\
\text { (rural) }\end{array}$} & \multicolumn{2}{|c|}{$\begin{array}{c}\text { Cuartel } 3 \\
\text { (rural) }\end{array}$} & \multicolumn{2}{|c|}{$\begin{array}{c}\text { Cuartel } 4 \\
\text { (rural) }\end{array}$} & \multicolumn{2}{|c|}{$\begin{array}{c}\text { Cuartel } 5 \\
\text { (rural) }\end{array}$} & \multicolumn{2}{|c|}{ Total } \\
\hline & Cant & $\%$ & Cant & $\%$ & Cant & $\%$ & Cant & $\%$ & Cant & $\%$ & Cant & $\%$ & Cant & $\%$ \\
\hline Azotea & 26 & 26,5 & 6 & 6 & 23 & 15,5 & 7 & 4,2 & 14 & 15,7 & 8 & 5,2 & 84 & 11,1 \\
\hline Madera & 7 & 7,1 & 8 & 8 & 2 & 1,3 & 10 & 6 & 6 & 6,7 & 3 & 1,9 & 36 & 4,8 \\
\hline Paja & 65 & 66,3 & 86 & 86 & 123 & 83,1 & 150 & 89,8 & 69 & 77,5 & 144 & 92,9 & 637 & 84,1 \\
\hline Total & 98 & 100 & 100 & 100 & 148 & 100 & 167 & 100 & 89 & 100 & 155 & 100 & 757 & 100 \\
\hline
\end{tabular}

\begin{tabular}{|l|c|c|c|c|c|c|c|}
\hline $\begin{array}{l}\text { Personas } \\
\text { por casa }\end{array}$ & 6,5 & 5,4 & 6,5 & 4,4 & 6,92 & 5,27 & 5,6 \\
\hline $\begin{array}{l}\text { Personas } \\
\text { por flia. }\end{array}$ & 4,65 & 5,6 & 6,6 & 5,99 & 6,69 & 4,23 & 5,5 \\
\hline
\end{tabular}

* Se incluyen aquí en los datos del cuartel 3 las libretas 3 y 23.

por 10 de ancho $\left(225 \mathrm{~m}^{2}\right)$ de 9 cuartos con umbrales y pisos de piedra o de mosaico de mármol, o la de Agustín Reyes de 24 varas de largo por 16 de ancho $\left(288 \mathrm{~m}^{2}\right)$ que con sus habitaciones empapeladas, con cielo raso, estufas y piso de baldosa, a más de otros detalles, expresan un indudable bienestar ${ }^{32}$.

32 «La propiedad comprende campos, quinta, etc y la casa incluye objetos como espejos, un órgano, muebles de caoba...», Archivo General de la Nación, Buenos Aires, Suc. 7828, Agustín Reyes y Gonzala Ortega de Reyes, 1859. 


\section{Mapa 2. SAN Vicente SEGÚN SUS VeCinOS (1853)}

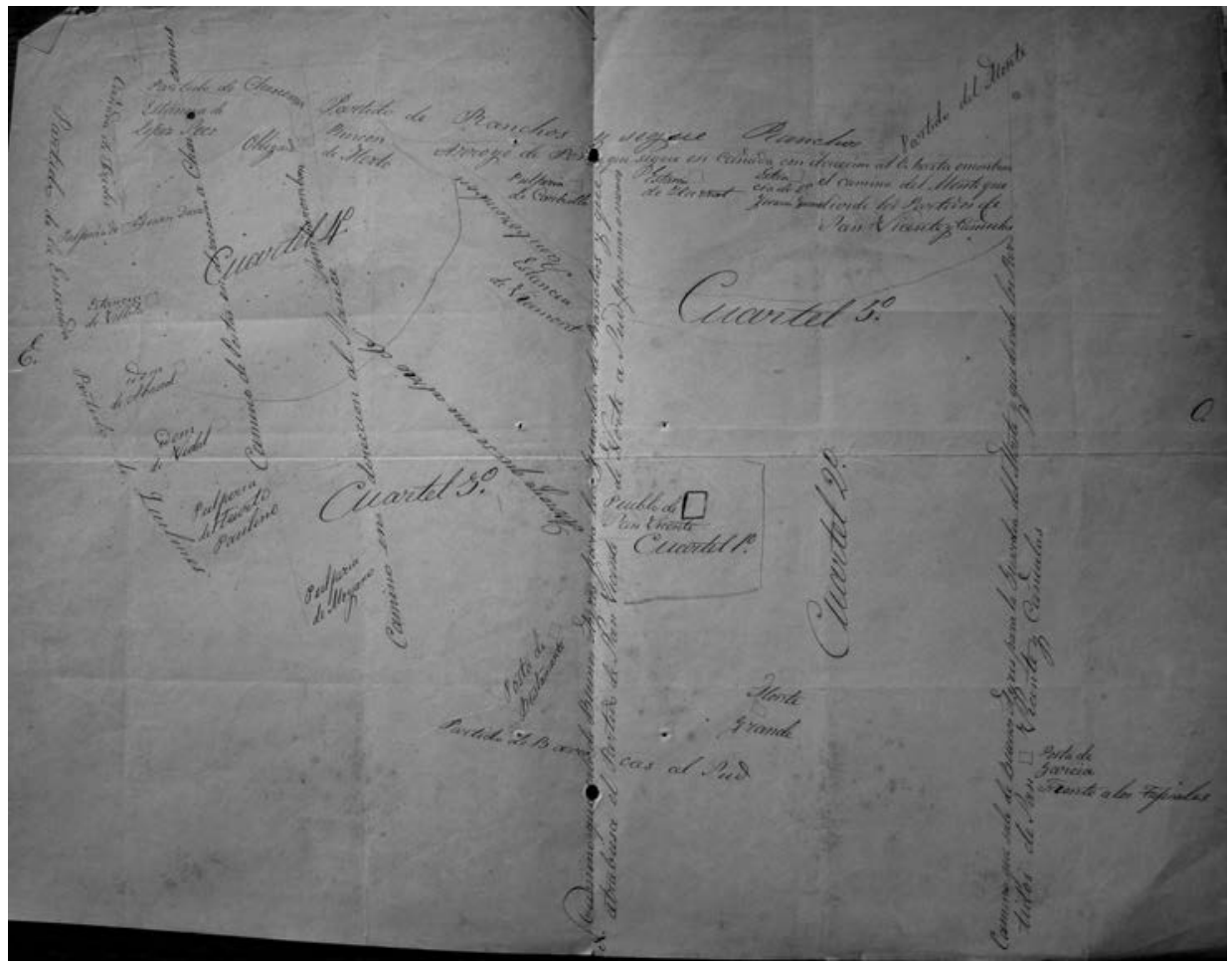

Límites de San Vicente en 1853 (autor anónimo).

Fuente: Archivo de Geodesia y catastro de la Provincia de Buenos Aires.

Mientras que el cuartel 4 es el que avanza más hacia el sur, limita con el partido de Chascomús, pese a ser el que cuenta con menos habitantes, es la zona que tiene casas más densamente pobladas y familias más numerosas, superando incluso a las del pueblo. Esto sugiere explotaciones de mayor extensión, lo que no podemos comprobar basándonos exclusivamente en el censo. En ambos cuarteles predomina la población argentina, aunque también se han instalado algunas familias italianas (ver anexo, cuadro 1).

En el extremo opuesto, en el cuartel 5, que limita con Monte, es donde predominan más fuertemente las casas de paja, las familias son menos numerosas y viven menos personas por casa. Son mayoritariamente argentinos quienes están allí instalados, hay muy pocos extranjeros y es igualmente en esa zona que se concentra la mayor cantidad de jornaleros, lo que lleva a deducir que estamos ante la zona más pobre del partido. 


\section{RESIDENTES «ILEGÍTIMOS» Y «MANCEBOS»}

Se debía anotar en el censo cuando los pobladores eran «ilegítimos»o «mancebos», es decir cuando eran hijos de padres no casados o que vivían en pareja sin haber formalizado la relación por la vía religiosa. Este es uno de los rubros donde más se percibe la visión que el propio censista tuviera de la cuestión: en algunos cuarteles se registran uniones de hecho o hijos ilegítimos en proporciones perfectamente comparables a las de otras zonas de la campaña de Buenos Aires, mientras que en otros no los hay en absoluto o incluso se infiere, en el caso de los mancebos, diferentes concepciones detrás de ese concepto entre los empadronadores. Así, mientras lo más habitual y corriente es que se considere mancebos a los que viven en unión ilegítima, algunos censistas - una minoría- declaran mancebos a aquellos individuos que ve disponibles en el «mercado matrimonial», por ejemplo Santiago Descalso (14 años, libreta 2) o Ursula Galeano (14 años, libreta 16) figuran en sendas listas con sus respectivos hermanos y son señalados «mancebos» por sus censistas, inscripción que en estos dos casos, fue corregida posteriormente en lápiz.

Una vez hechas estas aclaraciones, vemos que, si nos centramos en mujeres (los hombres mancebos son relativamente pocos) ${ }^{33}$, en el área urbana no hay mancebas y en la parte rural oscilan entre el 1,4\% y el 14\% de las mujeres, según quien sea el censista que hizo el relevo. En todo caso, esta condición es patrimonio casi exclusivo de los argentinos, lo que concuerda con lo que sabíamos al respecto: no hay prácticamente uniones ni hijos ilegítimos entre la población migrante ${ }^{34}$.

Un $15 \%$ de los niños de 0 a 14 años son declarados ilegítimos. Esto nos pone ante una evidencia: esa es una cifra mínima, ya que mientras en algunas libretas no consta ni un solo niño ilegítimo ${ }^{35}$, en otras abundan. Está claro que no todos los censistas otorgan la misma importancia a la cuestión o la ven con los mismos ojos, solo los registros parroquiales permiten reconstruir la ilegitimidad de manera fidedigna.

33 Se designa como «mancebos» al 4,4\% de las mujeres adultas y al $2 \%$ de los hombres. Las 24 «mancebas» son argentinas mientras que entre los 26 «mancebos», 23 son argentinos y europeos los otros tres. Los hombres son en su mayoría jornaleros, si bien hay cinco hacendados o estancieros y un comerciante. En cuanto a las mujeres, 2 de cada 3 no tienen ocupación, una es partera y las restantes se ganan la vida en el servicio doméstico.

34 Moreno, 1998. Otero, 2006, segunda parte.

35 Por ejemplo en las libretas 4 y 5 en las que tampoco se señalan «mancebos» o qué niños asisten a la escuela. 


\section{El MUNDO DEL TRABAJO}

Los censistas tenían por instrucciones tomar nota de los niños que concurrían a la escuela hasta los 14 años y de los que tuvieran una ocupación a partir de esa edad. Sin embargo algunos de ellos anotaron las tareas desempeñadas por los menores, lo que nos permite constatar la previsible entrada temprana al mundo del trabajo: se ganan la vida como jornaleros o boyeros ${ }^{36}$ 27 varones de 13 años o menos y seis niñas, aunque en el caso de las niñas, las ocupaciones son más variadas, hay también tres domésticas (una de ellas tiene 6 años y es sirvienta, otra de 11 años es cocinera), una jornalera, una cigarrera y una tejedora.

Estos niños representan claramente «la punta del iceberg», sin duda eran muchos más los que trabajaban, fuera o no a cambio de un jornal. Un aspecto interesante es que tres niños, combinan el trabajo con la escuela.

Retengamos para nuestro análisis, siguiendo el criterio del censo, solamente los mayores de 14 años. Contamos con 3.823 habitantes, 2.079 hombres y 1.744 mujeres $^{37}$.

Si nos detenemos en la ocupación de los que tienen entre 14 y 19 años vemos que, mientras el nivel de actividad para las mujeres es de un $25 \%$ (sean argentinas o extranjeras), para los hombres hay una diferencia significativa, mientras $81 \%$ de los jóvenes extranjeros trabajan, sólo un $49 \%$ de los jóvenes argentinos declaran una ocupación. Este dato puede inducirnos a deducir una entrada en el mundo del trabajo más temprana para los extranjeros, lo que sin duda sería un error de interpretación. Los jóvenes argentinos, al igual que los hijos de familias extranjeras de migración más antigua -ya «integrados» y por ende con una situación más consolidada- también participaban en las actividades de la explotación familiar, solo que al no cobrar un jornal por su trabajo, era posible que el censista no lo considerase una ocupación y no lo inscribiera como tal. Paralelamente, la mayoría de los extranjeros recibía, efectivamente, una remuneración por sus actividades, lo que les valía que no se dudara en atribuirles una ocupación ${ }^{38}$.

36 Denominación que recibían quienes se ocupaban de bueyes.

37 A la hora de ocuparnos de las actividades, hemos tenido que excluir de nuestra base de datos dos libretas, las n..$^{\circ} 3$ y 23 , ambas de zona rural, del cuartel $3 .^{\circ}$. En estos dos casos los censistas, inscribieron las ocupaciones de forma confusa, volviéndolas inexplotables. Esto representó excluir 426 personas (casi 10\% de los habitantes de San Vicente).

38 Cacopardo y Moreno (1995, cap. 1) señalan para los italianos de Luján la elevada incorporación al trabajo desde los 14 años, mientras se retrasaba el ingreso a la actividad entre los argentinos. Sin embargo, en Luján las mujeres italianas habrían estado más presentes en el mundo laboral que las argentinas. 
En cuanto al conjunto de los adultos, los hombres que declaran una actividad son $1.164(88,8 \%)$ y las mujeres $276(27,8 \%)$.

Cuadro 3. San Vicente, 1869. Trabajadores mayores de 14 años

\begin{tabular}{|l|c|c|c|c|c|c|}
\cline { 2 - 7 } \multicolumn{1}{c|}{} & Total & \% & $\begin{array}{c}+ \text { de } \mathbf{1 4} \\
\text { años }\end{array}$ & \% & $\begin{array}{c}\text { Declaran } \\
\text { actividad }\end{array}$ & \% \\
\hline Hombres & 2.079 & 54,4 & 1.311 & 56,9 & 1.164 & 80,8 \\
\hline Mujeres & 1.744 & 45,6 & 994 & 43,1 & 276 & 19,2 \\
\hline Total & 3.823 & 100 & 2.305 & 100 & 1.440 & 100 \\
\hline
\end{tabular}

Cuadro 4. San Vicente, 1869. Nivel de aCtividad de los trabajadores MAYORES DE 14 AÑOS

\begin{tabular}{|l|c|c|c|c|c|c|c|c|c|c|c|c|}
\cline { 2 - 13 } \multicolumn{1}{c|}{} & \multicolumn{3}{c|}{ Pueblo } & \multicolumn{3}{c|}{ Ejido } & \multicolumn{3}{c|}{ Rural } & \multicolumn{3}{c|}{ Total } \\
\cline { 2 - 12 } \multicolumn{1}{c|}{} & Pres.* & $\begin{array}{c}\text { Acti- } \\
\text { vos }\end{array}$ & $\%$ & Pres* & $\begin{array}{c}\text { Acti- } \\
\text { vos }\end{array}$ & \% & Pres* & $\begin{array}{c}\text { Acti- } \\
\text { vos }\end{array}$ & \% & Pres* & $\begin{array}{c}\text { Acti- } \\
\text { vos }\end{array}$ & \% \\
\hline Hombres & 199 & 184 & 92,5 & 93 & 87 & 93,5 & 1.019 & 893 & 87,6 & 1.311 & 1.164 & 88,8 \\
\hline Mujeres & 167 & 56 & 33,5 & 69 & 18 & 26 & 758 & 202 & 26,6 & 994 & 276 & 27,8 \\
\hline Total & 366 & 240 & 65,6 & 162 & 105 & 64,8 & 1.777 & 1.095 & 61,6 & 2.305 & 1.440 & 62,5 \\
\hline
\end{tabular}

Pres*: Presentes.

Como es habitual, tanto entre hombres como entre las mujeres, la zona urbana se muestra más dinámica que la rural declarando una mayor cantidad de trabajadores ${ }^{39}$. La concentración de actividades comerciales o artesanas en el pueblo, genera mayores posibilidades de tareas remuneradas. El ejido, siendo el àrea de chacras y quintas que rodeaba el pueblo, se muestra aquí, al igual que en Mercedes ${ }^{40}$ como una zona de transición entre ambos espacios, donde residirían pobladores susceptibles de trabajar tanto en la zona rural como urbana del pago.

\section{Las mujeres y sus ocupaciones remuneradas}

Como veíamos más arriba, las mujeres son más activas en el área urbana $(33,5 \%)$ que en la rural $(26,6 \%)$, sin embargo, no hay que olvidar que, tal

39 Contente y Barcos, 2016

40 Barcos, 2013. 
como lo sugeríamos para los jóvenes, la ocupación inscrita implica una remuneración y que en la zona rural más frecuentemente que en la urbana, ellas se integrarían naturalmente en las actividades de la explotación sin que por lo tanto, se lo considerara una ocupación digna de ser anotada.

Cuadro 5. San Vicente, 1869. Actividades deClaradas Por laS mujeres

\begin{tabular}{|l|c|c|c|c|c|}
\cline { 2 - 6 } \multicolumn{1}{c|}{} & Pueblo & Ejido & Rural & Total & \% \\
\hline «Patronas» agrícolas & - & 2 & 35 & 37 & 13,4 \\
\hline Mano de obra agrícola & - & 1 & 23 & 24 & 8,7 \\
\hline Servicio doméstico & 45 & 22 & 122 & 189 & 68,5 \\
\hline Artesanas & 6 & & 7 & 13 & 4,7 \\
\hline Otras & 5 & & 8 & 13 & 4,7 \\
\hline Total & 56 & 25 & 195 & 276 & 100 \\
\hline
\end{tabular}

Ahora, entre aquellas que declaran una actividad, la gran mayoría (68,5\%), están empleadas en servicio doméstico (cocineras, lavanderas, sirvientas, costureras), mientras que algo más de una cada cinco (22,1\%) se desempeñan en el mundo agrícola. Tampoco en el caso de las mujeres, debemos perder de vista la eventual combinación de diversas actividades, característica propia del mundo rural.

El abanico de ocupaciones posibles para las mujeres es muy semejante al encontrado en otras zonas agrícolas como Areco o Mercedes ${ }^{41}$.

Si cruzamos las actividades con el estado civil, vemos que quienes más trabajaban eran las viudas (una cada dos), seguidas por las solteras (una cada tres) y quedan en último lugar las casadas (1 cada 7). Evidentemente, son las solteras y viudas quienes están más expuestas a necesitar ganarse la vida fuera del grupo doméstico ${ }^{42}$.

41 Cf. Garavaglia, 2009. Barcos, 2013. Contente y Barcos, 2015.

42 Moya (2009) considera que el estado civil es el factor que más influye para determinar la participación de las mujeres en el mercado laboral. Indica que en Buenos Aires en 1855 entre las inmigrantes españolas trabajaban $78 \%$ de las mujeres de más de 16 años, lo que se repartía en $73 \%$ de las separadas, $54 \%$ de las viudas, y $40 \%$ de las casadas y que estas diferencias se agudizaron en 1869 y en el período 1894-1910. Si bien, el estudio de Moya se circunscribe a la comunidad española y a la ciudad de Buenos Aires (no hay que olvidar que hay más posibilidades de trabajo remunerado y mayor presencia de mujeres solas en las ciudades), la relación entre estado civil y trabajo entre las mujeres se observa igualmente en San Vicente rural. 
Cuadro 6. San Vicente, 1869. Actividades de las mujeres SEGÚN EL ESTADO CIVIL

\begin{tabular}{|l|c|c|c|c|c|c|}
\cline { 2 - 7 } \multicolumn{1}{c|}{} & \multicolumn{2}{c|}{ Solteras } & \multicolumn{2}{c|}{ Casadas } & \multicolumn{2}{c|}{ Viudas } \\
\cline { 2 - 7 } \multicolumn{1}{c|}{} & cantidad & $\mathbf{\%}$ & cantidad & $\mathbf{\%}$ & cantidad & \% \\
\hline «Patronas» agrícolas & 2 & 1,4 & 11 & 20,7 & 24 & 28,9 \\
\hline Mano de obra agrícola & 7 & 5 & 5 & 9,4 & 12 & 14,5 \\
\hline Servicio doméstico & 117 & 84,8 & 30 & 56,6 & 40 & 48 \\
\hline Artesanas & 8 & 5,8 & 2 & 3,8 & 3 & 3,6 \\
\hline Otras & 4 & 2,9 & 5 & 9,4 & 4 & 4,8 \\
\hline Total & 138 & 100 & 53 & 100 & 83 & 100 \\
\hline
\end{tabular}

Hay algunos aspectos que se desprenden del censo a propósito de las actividades, por ejemplo, las mujeres solteras y viudas predominan en el servicio doméstico mientras que las casadas, si bien están menos presentes en ese sector de actividad, son las únicas que, junto con las amancebadas, encuentran una ocupación como peonas o jornaleras ${ }^{43}$ : el universo de las tareas agrícolas asalariadas era eminentemente masculino y las mujeres no se conchabarían solas fácilmente en este tipo de actividades.

Algunas mujeres se ganaban la vida como artesanas, hay varias cigarreras $^{44}$ censadas tanto en la zona urbana como rural, muchas costureras y unas pocas tejedoras y bordadoras, ocupaciones que ofrecían la ventaja de poder realizarse en el domicilio, sin descuidar las tareas hogareñas.

La categoría «otras» cubre aquí las ocupaciones que serían más prestigiosas para las mujeres, como las de comerciante, maestras, monitoras que, como era de prever, eran poco numerosas $(4,7 \%$ del total).

Hemos denominado «patronas agrícolas», a aquellas que presumiblemente se encontraban al frente de una explotación. Dado que no hay división entre las unidades, no siempre es obvio distinguir entre las que eran jefas de familia de una explotación y las que trabajaban para completar sus ingresos. Sin embargo, se imponen algunas evidencias. En ciertas ocupaciones como la de hacendada, estanciera, chacarera o comerciante casi la totalidad de las

43 Garavaglia (2009) en su análisis del censo de Areco en 1869 nota que ninguna mujer casada se gana la vida haciendo servicio doméstico.

Si miramos caso por caso, todas las peonas o jornaleras son casadas o mancebas, y están acompañadas por el marido o compañero. Hay también una jornalera casada cuyo marido no está presente sin embargo, aparece junto a ella su suegra de 70 años conchabada también como jornalera.

44 Que confeccionaban o vendían cigarros. 
mujeres son viudas (63\%) o casadas $(29,7 \%)$. Aunque, en este último caso, los maridos están ausentes, su nombre no se encuentra en el censo junto al de la esposa. Sin duda, estas mujeres han «heredado» su situación: la ausencia o muerte del marido las ha llevado al frente de la explotación o el comercio que muy probablemente ayudaron a construir, pero en una situación a la que tenían muy pocas posibilidades de llegar solas, sin que el marido abriera previamente el camino.

En fin, el trabajo doméstico es lo que permite a la mayoría de las mujeres subvenir a sus necesidades ${ }^{45}$.

\section{El trabajo masculino}

En el área rural 88\% de los hombres adultos declaran una actividad mientras que en la zona urbana, es el caso del $92,5 \%$.

Cuadro 7. San Vicente, 1869. Síntesis ocupaciones masculinas, ÁREAS RURAL Y URBANA

\begin{tabular}{|l|c|c|c|c|c|c|c|c|}
\cline { 2 - 10 } \multicolumn{1}{c|}{} & \multicolumn{2}{c|}{ Urbano } & \multicolumn{2}{c|}{ Ejido } & \multicolumn{2}{c|}{ Rural } & \multicolumn{2}{c|}{ Total } \\
\hline \multicolumn{1}{|c|}{ Sector de actividad } & Cant & $\%$ & Cant & $\%$ & Cant & $\%$ & Cant & $\%$ \\
\hline Tareas agrícolas & 8 & 4,3 & 43 & 32,1 & 359 & 42,4 & 410 & 35,2 \\
\hline $\begin{array}{l}\text { Dependientes en tareas agrí- } \\
\text { colas }\end{array}$ & 66 & 35,9 & 73 & 54,5 & 421 & 49,8 & 560 & 48,1 \\
\hline $\begin{array}{l}\text { Actividades artesanales, co- } \\
\text { merciales y profesionales }\end{array}$ & 99 & 53,9 & 18 & 13,4 & 56 & 6,6 & 173 & 14,9 \\
\hline $\begin{array}{l}\text { Dependientes en actividades } \\
\text { artesanales, comerciales y } \\
\text { profesionales }\end{array}$ & 11 & 6 & - & & 10 & 1,2 & 21 & 1,8 \\
\hline Total & 184 & 100 & 134 & 100 & 846 & 100 & 1.164 & 100 \\
\hline
\end{tabular}

Como era previsible, las actividades agrícolas ocupan la gran mayoría de los hombres en la zona rural, mientras que los artesanos y comerciantes están instalados principalmente en el pueblo y el ejido. Llama la atención la importante proporción de jornaleros que residen en la zona urbana, lo que probablemente esté relacionado con las actividades en el ejido. Por otra parte, hay

45 Para mayores precisiones sobre el trabajo femenino en San Vicente, ver Contente, 2010. A propósito del trabajo de las mujeres migrantes y argentinas para este período en términos generales, consultar Cacopardo, 2011, en particular cap. 4. 
que recordar que, como mencionábamos, el pueblo de San Vicente llevaba relativamente poco tiempo en ese lugar, quizás por ese motivo, la actividad urbana no se encontraba tan desarrollada como podía estarlo en otros pueblos $^{46}$.

La presencia de 16 albañiles, 8 carpinteros y cuatro herreros sugiere que se construye activamente, mientras que la variedad de oficios y actividades nos habla de un pueblo dinámico y próspero: además de los ineludibles horneros (de ladrillos), verduleros o fonderos, San Vicente cuenta entre sus pobladores, un par de médicos y curanderos, varios maestros, un escribano, un escribiente y cantidad de artesanos como alpargatero, sastre, peinetero u hojalatero.

Como decíamos, la mayor concentración de extranjeros en la zona se encuentra justamente en el pueblo y en el ejido (son migrantes $40 \%$ de los habitantes del pueblo y $28 \%$ del ejido), donde ejercen una importante variedad de oficios artesanales, los 12 panaderos y el confitero son de origen europeo, al igual que la mayoría de los zapateros y demás oficios mencionados ${ }^{47}$. Son los migrantes quienes, sin duda, han estado directamente implicados en la construcción de las casas de «azotea» (de material) y de madera que se encuentran, en su mayoría entre el pueblo, el ejido y el cuartel 2.

Esto se relaciona con la prosperidad del pueblo, por supuesto, pero igualmente, como adelantábamos, con la presencia y el savoir faire de estos artesanos extranjeros.

En cuanto a la zona rural, más allá de las ocupaciones previsibles como las de labradores, estancieros o peones, abundan igualmente los pastores, reseros, graseros, boyeros, medianeros, tercianeros o trenzeros ${ }^{48} \ldots$ en fin, las relacionados con las tareas agrícolas y sus necesidades como pueden ser igualmente los carreros o carreteros.

46 Como por ejemplo en Mercedes, que era un pueblo claramente más dinámico que San Vicente, lo que probablemente estuviera igualmente relacionado a la mayor distancia que lo separaba de Buenos Aires (unos $100 \mathrm{~km}$, mientras San Vicente se encuentra a escasos $50 \mathrm{~km}$ de la capital) Contente y Barcos, 2016. A propósito de la urbanización en los diferentes partidos de la campaña bonaerense según fuentes fiscales consultar, Gelman y Santilli, 2011.

47 Por ejemplo, todos los herreros son de origen europeo, hay solo un argentino entre los 13 carpinteros, dos entre los 13 albañiles y solo tres de los 16 zapateros son nativos.

48 Se llamaba reseros a todos aquellos que trabajaban con ganado, en especial quienes se ocupaban de llevarlo de un lugar a otro. Los graseros recolectaban y probablemente preparaban la grasa que se utilizaría luego para diferentes finalidades como las confección de velas, mientras que los «trenzeros» o «sogueros» eran artesanos que confeccionaban objetos a partir de tientos trenzados que podían utilizarse igualmente en las actividades agrícolas (las fustas, riendas...). 


\section{El área rural: el trabajo dependiente y por su propia cuenta y riesgo}

Intentaremos estimar la proporción de hombres ${ }^{49}$ que trabajan en actividades rurales por su cuenta y en relación de dependencia. Si bien el paso del trabajo dependiente a la instalación por su propia cuenta y riesgo puede estar ligado a las etapas del ciclo de vida ${ }^{50}$, este proceso no parece haber sido tan fluido en el San Vicente de 1869 como lo habría sido precedentemente ${ }^{51}$. La saturación del espacio y la intensidad que alcanzaba la explotación de la tierra había modificado seriamente estas condiciones. Dado que el censo no nos da una indicación al respecto, haremos un cálculo que nos permita tener una idea, aunque sea poco precisa, de esta relación. Se trata de una estimación simplificadora, ya que al considerar la ocupación que da el censo como si fuera la única del individuo, estamos obviando la pluriactividad propia de las unidades campesinas que incluyen, por ejemplo, la posibilidad de completar los ingresos que pudiera producir el trabajo en su explotación con un trabajo artesanal, asalariado o el que fuera ${ }^{52}$.

Está claro que los hacendados, estancieros y labradores trabajan por su cuenta y que los peones y jornaleros son dependientes, pero la clasificación se presta a confusión en el caso de los pastores, puesteros, medianeros... Haremos entonces dos cálculos, uno contando a estos últimos entre los patrones y otro excluyéndolos de ese grupo para contarlos entre los dependientes. Así, si consideramos los individuos que son «patrones» (hacendados, estancieros...), junto con los que se puede considerar que trabajan por su cuenta (pastores, puesteros, medianeros...), tenemos 410 individuos "cuentapropistas». Si los ponemos en relación con los 560 dependientes rurales (capataces, peones, jornaleros, etc.), llegamos a la conclusión de que hay 1,4 trabajador

49 Excluimos las mujeres de nuestra estimación ya que además de ser minoría, distorsionarían las cifras al estar, por ejemplos sobrerrepresentadas en algunos grupos (como el de «patrones») y prácticamente ausentes entre peones y jornaleros.

50 Chayanov, 1974.

51 Contente, 2015: 202-205.

52 Se trata de las características propias de la confección de toda lista, que conlleva un inevitable proceso de abstracción y de reducción del contenido con los consecuentes inconvenientes para restituir su significado, Goody, 1979: 170-183; 2007, cap. VII. En cuanto a esta complejidad en el uso concreto y preciso de categorías ocupacionales en la campaña bonaerense del siglo XIX para definir una actividad o incluso un estatus social, Fradkin, 1993.

A propósito de la posible combinación entre trabajo por su cuenta y asalariado cabe remitir a la estimulante «polémica» que tuvo lugar en las páginas del Anuario del IEHS bajo el título "Gauchos, campesinos y fuerza de trabajo en la campaña rioplatense colonial", Mayo, 1987. Amaral, 1987. Garavaglia 1987. Gelman, 1987 y más recientemente a otros trabajos como por ejemplo Gelman y Santilli, 2014. 
dependiente por patrón (o trabajador «independiente») o 0,7 «patrón» por trabajador dependiente.

En la segunda posibilidad, consideraremos que esos pastores, lecheros, etc., no es seguro que trabajen por su cuenta, de modo que los excluiremos de este grupo para sumarlos a los dependientes. En ese caso, tendremos solamente 282 «patrones» (hacendados, estancieros, labradores, chacareros), ya que con ellos no hay lugar a dudas, son efectivamente independientes y 686 dependientes (lo que incluye a los «dudosos» puesteros, pastores, etc.) tenemos entonces 0,4 patrón por cada trabajador dependiente o 2,4 dependientes por patrón.

Si nos atenemos al primer razonamiento, el riesgo es que probablemente no todos los que contamos como «cuentapropistas» lo sean (cómo saber si los pastores están percibiendo un salario o si se ocupan de su propio rebaño?) y si consideramos la segunda posibilidad, entre los dependientes es más que probable que se cuenten además de lo que hemos mencionado, los peones de algún tropero o carretero que no están incluidos entre los «patrones», lo que sesga también la estimación.

Evidentemente la cantidad de dependientes por patrón se encuentra en algún punto entre los dos resultados, es decir hay entre 1,4 y 2,4 trabajadores dependientes por «cuentapropistas», mientras que la relación de patrones por dependientes estaría entre 0,7 y $0,4^{53}$.

En todo caso lo que está claro es que esta situación se ha modificado bastante con el correr del siglo XIX. El censo de 1815, al delimitar las unidades y permitirnos saber así quien es mano de obra contratada y dónde, es bastante preciso al respecto y nos permite afirmar que en ese entonces, 600 labradores y criadores se repartían 396 peones y 322 criados (718 dependientes en total en unidades censales de labradores y estancieros), lo que representa 1,2 peones por patrón o 0,8 patrón por peón. Esta proporción en 1869 se encuentra sin duda, insistimos, entre las dos estimaciones avanzadas, pero de cualquier modo, sea cual sea la cifra que retengamos de nuestra estimación para 1869 , el censo prueba desde otra perspectiva lo que se podía suponer y que delatan asimismo otra fuentes: se va volviendo cada vez más difícil ser un productor independiente y hay cada vez menos patrones y más peones y jornaleros ${ }^{54}$.

53 Gelman y Santilli (2015) estiman que en 1815 para el conjunto de la campaña bonaerense se contaban 1,2 trabajador por cada productor independiente, mientras que para 1869 se registraban 3,6 dependientes por cada productor instalado por su cuenta.

54 Gelman y Santilli, 2011; 2013; 2015. 


\section{LOS POBLADORES, LAS ACTIVIDADES Y SUS ORÍGENES}

Nos detendremos aquí en las actividades más representativas para ver la nacionalidad de quienes ejercían esas ocupaciones, incluyendo a los de habla inglesa y teniendo en cuenta que, al ser poco numerosos y una comunidad más reducida que las demás, las suyas son cifras a considerar con suma prudencia. Debemos aclarar que para subsanar errores, hemos fusionado en este grupo a todos los de habla inglesa presentes (ingleses, irlandeses y escoceses) porque sospechamos que se les puede haber atribuido el origen de manera poco rigurosa ${ }^{55}$.

Cuadro 8. San Vicente, 1869. OríGenes de la población activa, SEGÚN LAS OCUPACIONES (EN PORCENTAJES)*

\begin{tabular}{|l|c|c|c|c|c|}
\cline { 2 - 6 } \multicolumn{1}{c|}{} & Argentinos & Italianos & Franceses & Españoles & Ingleses \\
\hline \%ombres con ocupación atribuida & 43,5 & 25,3 & 10,6 & 11 & 3,8 \\
\hline
\end{tabular}

\begin{tabular}{|l|c|c|c|c|c|}
\hline Hacendados, estancieros & 26,1 & 0,7 & 4,8 & 8,6 & 23,8 \\
\hline Labradores, chacareros & 3,4 & 22 & 8,1 & 5,5 & 2,4 \\
\hline Jornaleros & 39,3 & 38,8 & 37,1 & 39,8 & 42,8 \\
\hline Peones (labradores, puesto, etc.) & 8,7 & 8,1 & 9,7 & 8,6 & \\
\hline Medianeros, tercianeros & 6,7 & 0,7 & 4 & 3,1 & 23,8 \\
\hline Comerciantes & 3 & 5,4 & 8,1 & 10,2 & \\
\hline Otras ocupaciones & 12,8 & 24,3 & 28,2 & 24,2 & 7,1 \\
\hline Total & 100 & 100 & 100 & 100 & 100 \\
\hline
\end{tabular}

* Al igual que en censo, hemos considerado población activa a todos los mayores de 14 años. Recordemos que habían 1.311 hombres mayores de 14 años, 1.164 con una ocupación atribuida. Están representados aquí 96\% de los extranjeros que residían en San Vicente y 66\% de la población masculina activa.

Se ven algunas particularidades interesantes en función de los orígenes. Por una parte que todas las nacionalidades proveen cantidades comparables de jornaleros, entre 37 y $39,8 \%$.

Por otra parte, es tentador sumar peones y jornaleros ¿designan formas de trabajo diferentes? Hoy en día esos términos nos sugieren que se llama-

55 Los sanvicentinos de «habla inglesa» son 100 personas (de todas las edades) de los cuales 71 son declarados ingleses, 15 irlandeses y los 14 restantes escoceses. 
ría peones a quienes trabajaban en relación de dependencia regularmente y jornaleros a quienes eran contratados por día a cambio de un jornal. Se podría considerar incluso que el neto predominio de jornaleros con respecto a los peones, refuerza la hipótesis avanzada a propósito de la creciente dificultad para ser productor independiente regular en esta zona. Algunos autores afirman sin embargo que la demanda de jornaleros expresa la de una mano de obra más especializada que la del peón mensual ${ }^{56}$. Es difícil llegar a alguna conclusión concreta a partir de la información contenida en el censo, el hecho que en algunas libretas se alternen ambas categorías mientras en otras encontramos exclusivamente peones o jornaleros parece indicar que no todos los censistas hacían una diferencia conceptual entre ambas denominaciones ${ }^{57}$.

En fin, si sumamos peones y jornaleros, quedamos en proporciones comparables dentro de cada comunidad (oscila entre $48 \%$ entre los trabajadores argentinos y $47 \%$ entre los italianos).

En 1815 un $31 \%$ de los jefes de familia patriotas $^{58}$ de San Vicente se declaraban labradores y un 44\% criadores. En 1869 los argentinos representan sólo $3 \%$ de los labradores y un $26 \%$ de los estancieros y hacendados. Esto significa que en ese lapso de tiempo, mientras, los pobladores de origen italiano han ido acaparando la agricultura, la mayor parte de los argentinos se han volcado a la cría de ganado. Son italianos quienes se encargan cada vez más de la producción de cereales, seguidos de lejos por los «orientales» (nativos de la Banda Oriental del Uruguay) y franceses ${ }^{59}$.

Encontramos prácticamente la misma proporción de hacendados y estancieros entre los argentinos y entre los miembros de la comunidad de habla inglesa. Claro que en el caso de los ingleses, estamos hablando de una comunidad significativamente más pequeña, de solo 44 miembros, de los cuales 11 son estancieros o hacendados. Su capacidad para lograr instalarse en estos rubros está directamente relacionada con los conocimientos que han traído de sus países de origen y con el hecho que esta corriente migratoria había comenzado a llegar anteriormente que las provenientes de otras regiones, gracias

\footnotetext{
56 Gelman y Santilli, 2014.

57 Lo que ha sido verificado igualmente en otras zonas de la campaña bonaerense. Contente y Barcos, 2016.

58 Así los designa el censo de 1815 en San Vicente.

59 Cacopardo (1997) menciona que a menudo no saben andar a caballo, o les falta al menos la habilidad imprescindible para ocuparse del ganado.

De los 111 labradores y chacareros presentes, 66 son italianos, 18 argentinos, 9 franceses, y cuatro «orientales».
} 
a lo cual sus representantes habían tenido más tiempo para asentarse y consolidar su situación ${ }^{60}$.

No existen diferencias significativas entre franceses y españoles en cuanto al desempeño de ocupaciones ligadas a las actividades rurales. Sin embargo en las «otras ocupaciones» se perfilan algunas diferencias entre los oficios, encontrando más comerciantes entre los españoles y, como veíamos más arriba, artesanos especializados entre los franceses.

Veamos ahora estos datos desde otra perspectiva:

Cuadro 9. San Vicente, 1869. Ocupaciones de la Población activa MASCULINA SEGÚN LOS ORÍGENES (EN PORCENTAJES)

\begin{tabular}{|l|c|c|c|c|c|c|}
\hline $\begin{array}{c}\text { Hombres que } \\
\text { declaran la } \\
\text { ocupación }\end{array}$ & $\begin{array}{c}\text { Hacendado } \\
\text { estanciero }\end{array}$ & $\begin{array}{c}\text { Labrador } \\
\text { chacarero }\end{array}$ & $\begin{array}{c}\text { Medianero } \\
\text { Tercianero }\end{array}$ & Jornalero & $\begin{array}{c}\text { Peones } \\
\text { (varios) }\end{array}$ & $\begin{array}{c}\text { Peón- } \\
\text { Labrador* }\end{array}$ \\
\hline Cantidad & 169 & 113 & 61 & 452 & 87 & 12 \\
\hline Porcentaje & $14,5 \%$ & $9,7 \%$ & $5,2 \%$ & $38,8 \%$ & $7,5 \%$ & $1 \%$ \\
\hline
\end{tabular}

\begin{tabular}{|l|c|c|c|c|c|c|}
\hline Argentinos & 78,7 & 15 & 59 & 44 & 50,6 & \\
\hline Ingleses & 6,5 & 0,9 & 16,4 & 4,2 & & \\
\hline Españoles & 5,9 & 6,2 & 6,6 & 11,3 & 12,6 & 8,3 \\
\hline Franceses & 4,1 & 8,8 & 8,2 & 10,4 & 12,6 & 8,3 \\
\hline Italianos & 1,2 & 62 & 3,3 & 25,4 & 14,9 & 75 \\
\hline Otros orígenes & 3,6 & 7 & 6,5 & 4,6 & 9,1 & 8,3 \\
\hline Total & 100 & 100 & 100 & 100 & 100 & 100 \\
\hline
\end{tabular}

* Aunque muchos trabajadores debían combinar tareas, esta categoría aparece solo en las libretas 9 y 10 , llevadas por un mismo censista.

Si observamos los hombres con una ocupación, 43\% son argentinos. Los hombres argentinos representan asimismo $78,7 \%$ de los hacendados y estancieros: son los nativos quienes dominan la cría de ganado, seguidos, de lejos por los miembros de la comunidad de habla inglesa que, siendo $4 \%$ de los trabajadores, representan $6,5 \%$ de los hacendados y estancieros.

En cuanto a peones y jornaleros, casi la mitad de la fuerza de trabajo dependiente, está compuesta por los nativos, seguidos por los italianos y demás grupos.

60 Sábato, 1989. 
Hay trabajadores que se declaran medianeros y tercianeros exclusivamente en los cuarteles 1 y $5^{61}$. Se trataba de personas que realizaban emprendimientos a medias o al tercio de los beneficios cultivando la tierra o criando ganados, bajo diferentes formas de contratos. En el caso del Río de la Plata estos convenios eran en su mayoría verbales o informales hasta que con la sanción del Código Civil fue indispensable registrarlos ante un escribano o autoridad competente. En este rubro son también básicamente argentinos quienes predominan, seguidos por los ingleses. Sin duda, también en este caso sería indispensable para los migrantes cierta permanencia en el lugar que les brindara la posibilidad de ganarse la confianza de algún propietario como para llegar a suscribir este tipo de convenio, por lo cual son sobre todo ingleses quienes podían acceder más fácilmente a esta condición.

En cuanto a los labradores y chacareros, son los italianos que, como veíamos, de a poco van monopolizando prácticamente el oficio: siendo $25 \%$ de los trabajadores, representan un $62 \%$ de los que se ganan la vida cultivando la tierra. Esta actividad cuenta también con algunos argentinos e igualmente franceses y españoles entre quienes la ejercen, aunque, como se puede ver, son franca minoría.

\section{LOS MIGRANTES Y SUS ACTIVIDADES}

Si bien el censo no contiene información a propósito de la estructura de las familias, el estado civil y la composición etaria de los migrantes nos dan algunas pistas para entrever algunas características de la llegada de las diferentes corrientes migratorias a San Vicente. En este contexto, el predominio de hombres solos en las edades más activas es una indicación de una corriente migratoria más reciente, mientras que la presencia de personas de mayor edad y de ambos sexos como es el caso aquí entre los ingleses, señalan una llegada anterior del grupo.

La comunidad más presente es la de los italianos (casi un $10 \%$ de los sanvicentinos), más de un $37 \%$ de ellos tiene entre 20 y 30 años, predominando ampliamente los hombres. En ese entonces hacía aún poco tiempo que habían comenzado a llegar migrantes de este origen, esta corriente se desarrollaría y afirmaría aún más en los años siguientes, lo que conllevaría la llegada e instalación de familias completas ${ }^{62}$.

61 Sin duda fueron incluidos en otros sectores por los demás censistas.

62 Devoto y Rosoli, 1985. 
Cuadro 10. San Vicente, 1869. Población mayor de 14 años, TRABAJADORES SEGÚN SEXO Y ORIGEN

\begin{tabular}{|l|c|c|c|c|c|c|}
\hline \multirow{2}{*}{\multicolumn{1}{c|}{ Origen }} & \multicolumn{3}{|c|}{ Hombres } & \multicolumn{3}{c|}{ Mujeres } \\
\cline { 2 - 7 } & $\begin{array}{c}\text { Mayores } \\
\mathbf{1 4} \text { años }\end{array}$ & $\begin{array}{c}\text { Declaran } \\
\text { ocupación }\end{array}$ & $\mathbf{\%}$ & $\begin{array}{c}\text { Mayores } \\
\mathbf{1 4} \text { años }\end{array}$ & $\begin{array}{c}\text { Declaran } \\
\text { ocupación }\end{array}$ & $\%$ \\
\hline Argentinos (1.445) & 627 & 506 & 80,7 & 818 & 240 & 29,3 \\
\hline Italianos (361) & 304 & 295 & 97 & 57 & 10 & 17,5 \\
\hline Franceses (169) & 129 & 124 & 96,1 & 40 & 3 & 7,5 \\
\hline Españoles (168) & 133 & 128 & 96,2 & 35 & 9 & 25,7 \\
\hline Orientales (24) & 20 & 20 & 100 & 13 & 8 & 61,5 \\
\hline Habla inglesa (71) & 49 & 44 & 89,8 & 22 & 4 & 18,2 \\
\hline
\end{tabular}

Las comunidades de españoles y franceses tienen un número de miembros similar, aunque la repartición por edades comporta diferencias, entre los españoles hay muy pocas personas mayores, se trata de un flujo migratorio incipiente y que alcanzará su pico en cuanto a llegada de inmigrantes algunas décadas después que el de italianos ${ }^{63}$. Mientras que los franceses han comenzado a migrar con anterioridad y encontramos miembros de su comunidad en todas las cohortes ${ }^{64}$.

En cuanto a los ingleses, son los menos numerosos y están más repartidos por todas la cohortes, son el grupo que lleva más antigüedad en la zona y, como decíamos, se muestran bien insertados en la comunidad local.

Otro dato, entre los adultos hay una mujer casada o viuda por 4,7 franceses, una por cada 5,9 españoles y una por cada 6,7 italianos. Lo que implica, por una parte, que en ese entonces los franceses migraban en familia más que los italianos o españoles y, por otra, permite igualmente explicar por qué veíamos más arriba que las mujeres francesas declaraban menos ocupaciones. Al llegar en familia, se centraban en las tareas informales ligadas a la explotación familiar, mientras que las españolas eran las que tenían, entre las migrantes, una mayor participación en el mundo del trabajo ${ }^{65}$.

\footnotetext{
63 A propósito de la evolución de las corrientes española e italiana ver Moya, 1998: 19.

64 En cuanto a la migración francesa consultar Otero, 1995.

65 Según José Moya (2009), en la ciudad de Buenos Aires 54\% de las mujeres mayores de 16 años declaraban una actividad.
} 


\section{EL NIVEL DE ALFABETIZACIÓN Y SU RELACIÓN CON LAS ACTIVIDADES}

Casi $42 \%$ de la población adulta declaraba saber leer y escribir. Sin embargo, detrás de esta cifra se disimulan varios elementos. Comenzaremos por comparar la población nacida en Argentina con la de origen europeo, sin perder de vista que en la categoría «migrante europeo» se esconden comportamientos culturales y tradiciones diversas y variadas ${ }^{66}$.

Si miramos el nivel de alfabetización globalmente, entre los mayores de 15 años tenemos:

\section{Cuadro 11. San Vicente, 1869. Alfabetización de los Mayores} DE 15 AÑOS SEGÚN EL ORIGEN

\begin{tabular}{|l|c|c|}
\cline { 2 - 3 } \multicolumn{1}{c|}{} & \multicolumn{2}{c|}{ Saben leer y escribir } \\
\cline { 2 - 3 } \multicolumn{1}{c|}{} & cantidad & $\mathbf{\%}$ \\
\hline Hombres argentinos (641) & 232 & 36,2 \\
\hline Hombres europeos (757) & 409 & 54 \\
\hline Mujeres argentinas (851) & 310 & 36,4 \\
\hline Mujeres europeas (195) & 71 & 36,4 \\
\hline Total (2.444) & 1.022 & 41,8 \\
\hline
\end{tabular}

Constatamos aquí que entre los extranjeros la proporción de quienes saben leer y escribir es más alta entre los hombres que entre las mujeres. Entre los argentinos no hay diferencia notable entre ambos sexos.

Es bien sabido que en Europa, en términos generales, la instrucción de los varones iba más lejos que la de las mujeres ${ }^{67}$ y eso se refleja claramente aquí, en la población presente en este rincón de la campaña de Buenos Aires.

Si nos detenemos en aquellos que sabían leer y escribir, es entre maestros, comerciantes y artesanos especializados (panaderos, carpinteros, etc.) que, tal como podíamos suponer, encontramos los niveles más altos de alfabetización, seguidos por los estancieros y hacendados (algo más de uno cada dos), mientras que un tercio de los labradores y jornaleros (33 y 35,2\% respectivamente) cuentan con este conocimiento.

66 Para obtener una mayor representatividad en nuestro estudio sobre las profesiones, están incluidos aquí los datos de las libretas 3 y 23 que habíamos apartado precedentemente. Hay que señalar que para 11 habitantes los censistas han omitido señalar si sabían leer y escribir.

67 Sobre ese tema ver, por ejemplo para el caso de Francia, la obra de Furet y Ozouf, 1977. 
Lo mismo sucede entre las mujeres, es entre las «patronas» agrícolas que encontramos la mayor proporción de alfabetizadas (una cada dos). En el otro extremo, entre las que se ganaban la vida gracias al servicio doméstico, sólo era una de cada cinco. Algunas diferencias aparecieron igualmente dentro de este grupo: $32,8 \%$ de las costureras sabían leer y escribir y sólo $9 \%$ de las lavanderas estaban en la misma situación.

Si miramos ahora según las nacionalidades, dado el pequeño número de efectivos que resulta de cruzar algunas ocupaciones con el origen de los migrantes, no es razonable evaluar el nivel de alfabetización entre todos los subgrupos $^{68}$. Por ese motivo daremos una mirada solo a las ocupaciones predominantes entre argentinos e italianos.

Vemos así que si un 36\% de los hombres argentinos saben leer y escribir, es igualmente el caso de la mitad de los estancieros, hacendados y labradores pero de uno de cada cuatro jornaleros.

En cambio entre los italianos, son 46,6\% los alfabetizados, aunque aquellos que saben leer y escribir se ganan la vida ante todo como comerciantes o artesanos: entre los labradores, no llegan a ser uno cada tres quienes pueden desenvolverse en este aspecto, lo que contrasta con los labradores argentinos nativos que sí se diferenciaban en este aspecto de peones y jornaleros.

Veamos qué pasaba con los niños.

\section{LOS NIÑOS Y LA ESCUELA}

Según sabemos, en San Vicente funcionaba una escuela desde 1828 aunque habría sido cerrada en tiempos de Rosas para abrir nuevamente en 1856 la de varones, y un año después, la de niñas ${ }^{69}$.

Casi un $21 \%$ de los niños iban a la escuela, seguramente más, ya que en algunas libretas se omite apuntarlo. En todo caso, los datos respecto a la escolarización de los menores, van en el mismo sentido que los de la alfabetización de los adultos, incluso si son pocos los efectivos entre los extranjeros.

Recordemos que los hijos de migrantes nacidos en Argentina se cuentan entre los argentinos, lo que está sesgando los datos, al incluir entre los nativos las familias migrantes con sus diferentes prácticas culturales. Aún así, no hay diferencias notables entre varones y niñas argentinos en cuanto a la frecuentación de la escuela, aunque la diferencia sí es relevante entre los extranjeros, cuyos hijos varones son más numerosos en la escuela que las mujeres, tanto

\footnotetext{
68 Moya, 2009.

69 Levene, 1941, vol 2: 645.
} 
Cuadro 12. San Vicente, 1869. Asistencia escolar Según El ORigen Y EL SEXO DE LOS NIÑOS

\begin{tabular}{|l|c|c|c|}
\hline \multicolumn{1}{|c|}{ Argentinos } & Niños presentes & Van a la escuela & \% \\
\hline Varones & 521 & 104 & 20 \\
\hline Niñas & 479 & 103 & 21,5 \\
\hline Total & 1.000 & 207 & 20,7 \\
\hline
\end{tabular}

\begin{tabular}{|l|c|c|c|}
\hline \multicolumn{1}{|c|}{ Extranjeros } & Niños presentes & Van a la escuela & $\mathbf{\%}$ \\
\hline Varones & 49 & 13 & 26,5 \\
\hline Niñas & 24 & 3 & 12,5 \\
\hline Total & 73 & 16 & 21,9 \\
\hline
\end{tabular}

en el medio rural como urbano. Obviamente estas familias conservan en este aspecto el modelo cultural que traen de sus patrias de origen.

Otro elemento, los niños de mayor edad, son proporcionalmente más numerosos yendo a la escuela que los más pequeños y esto se verifica en todas las zonas de San Vicente:

\section{Cuadro 13. San Vicente 1869: Asistencia escolar SEgún las edades Y ZONAS DE RESIDENCIA DE LOS NIÑOS*}

\begin{tabular}{|l|c|c|c|}
\cline { 2 - 4 } \multicolumn{1}{c|}{} & \multicolumn{3}{c|}{ Niños de 6 a 9 años } \\
\cline { 2 - 4 } \multicolumn{1}{c|}{} & $\begin{array}{c}\text { Niños } \\
\text { presentes }\end{array}$ & $\begin{array}{c}\text { van a la } \\
\text { escuela }\end{array}$ & $\%$ \\
\hline Pueblo & 62 & 31 & 50 \\
\hline Ejido & 57 & 11 & 19,3 \\
\hline Rural & 361 & 49 & 13,6 \\
\hline Total & 480 & 91 & 18,9 \\
\hline
\end{tabular}

\begin{tabular}{|c|c|c|}
\hline \multicolumn{3}{|c|}{ Niños de 10 a 13 años } \\
\hline $\begin{array}{c}\text { Niños } \\
\text { presentes }\end{array}$ & $\begin{array}{c}\text { van a la } \\
\text { escuela }\end{array}$ & \% \\
\hline 44 & 25 & 57 \\
\hline 59 & 19 & 32,2 \\
\hline 377 & 77 & 20,42 \\
\hline 480 & 121 & 25,2 \\
\hline
\end{tabular}

* Si apartamos las libretas que no inscriben niños asistiendo a la escuela, las cifras globales para el conjunto de San Vicente quedarían en un 24,1 \% entre los niños de 6 a 9 años y 30,4 \% entre los de 10 a 13.

Hay que agregar que si $53 \%$ de los niños que viven en el pueblo van a la escuela, son $25 \%$ los que van y viven en el ejido y sólo $17 \%$ de los que viven en el campo asisten a la escuela.

Si normalmente la explotación podría prescindir más fácilmente de la colaboración de los hijos más pequeños que de los grandes, de estos datos 
podemos inferir algunos elementos. Por un lado, que la mayor presencia de extranjeros en el pueblo y ejido que, según vimos, tendían a tener un mayor nivel de alfabetización, sobre todo entre los varones, habrá influido a la hora de enviar los niños a la escuela, abultando el número de niños, en las zonas donde residían más migrantes. Además, la escuela se encontraba en el pueblo, lo que dadas las distancias, también debía ser un factor disuasivo para que todos asistieran, sobre todo en el caso de los más pequeños, pudiendo los mayores acudir por sus propios medios. Esto sin duda ayudaría también a explicar por qué los niños de algunas zonas tenían más probabilidades que los de otras de aprender a leer y escribir.

\section{CONCLuSiones}

El censo abarca aspectos bien amplios y concretos del conjunto de la población e, incluso a través de las omisiones, nos aporta datos sobre la sociedad y sus habitantes: hemos visto que algunos censistas no consideran digno de mención el trabajo femenino o infantil, o no registran la ilegitimidad, probablemente por considerarla irrelevante o no verla como tal. Las personas que recogieron los datos han puesto involuntariamente a nuestro alcance, a través de los datos que consignaron, su visión de la realidad e indicios de una sociedad en plena evolución. La alfabetización de los adultos o la frecuentación de la escuela de los niños nos acercan también a diferencias en las pautas culturales de la población, prueban el previsible arraigo de tradiciones y costumbres traídas por los migrantes desde sus respectivas tierras de origen.

Ahora, más allá de los aspectos culturales que se dibujan en filigrana a través del censo ¿Qué aspectos concretos retenemos de este recorrido por San Vicente a través de sus «números»?

En primer lugar, la evolución de la relación entre trabajadores independientes y dependientes a lo largo de las décadas es significativa. Si en la primer mitad del siglo XIX no era siempre indispensable contar con un título de propiedad o pagar un arrendamiento para acceder a la explotación de la tierra, esta situación ya se había claramente terminado en 1869 , tal como se ha verificado igualmente a través de fuentes fiscales ${ }^{70}$.

El proceso de intensificación de la producción había convertido igualmente en inviables muchas unidades de pequeños y medianos propietarios que ya no podían vivir del fruto de su explotación ${ }^{71}$. En otro trabajo hemos podido

\footnotetext{
70 Gelman y Santilli, 2011; 2013; 2015.

71 Banzato y Lanteri, 2007.
} 
constatar a través de casos concretos como algunos descendientes de familias de San Vicente que eran acomodadas a principios de siglo, pese a conservar propiedades, se ganaban la vida como jornaleros hacia fines del siglo XIX o principios del $\mathrm{XX}^{72}$. Se trata de un proceso de vasto alcance relacionado con el reparto sucesorio de bienes que llevaba a la fragmentación de las propiedades, -que implicaba que al cabo de algunas generaciones las superficies no fueran suficientes para el sustento de una familia- pero también relacionado con las transformaciones que trajeron aparejados los cambios de la explotación agrícola. El censo refleja y constata entonces los cambios que se fueron operando en la estructura territorial y en el mercado de trabajo. Estos cambios estaban igualmente vinculados con el impacto producido en diversos órdenes por la migración y que condujeron a una «proletarización» de amplios sectores de la población local. Si algunos de los hombres que en otros tiempos estaban al frente de su propia explotación pasaron a ser jornaleros o capataces en tierras de nuevos patrones (patrones eventualmente extranjeros), para las mujeres significó también que fuera indispensable salir a ganarse la vida fuera del hogar. Recordemos que el censo delata la ausencia de hombres nativos que se encontraban movilizados en la guerra del Paraguay, o habían fallecido o resultado heridos en las diversas contiendas de los años anteriores, otro elemento que participó en la pérdida de estabilidad de las familias locales al tiempo que, ciertamente, facilitó para algunos de los extranjeros la inclusión en la sociedad local y que se ve reflejada igualmente en las otras zonas estudiadas como Mercedes o Areco ${ }^{73}$. Los migrantes pudieron entonces ayudar a suplir en las explotaciones el vacío dejado por los hombres del lugar y vieron mejoradas las probabilidades de encontrar una esposa local... dentro de lo que cabía con tantos hombres solteros disponibles en la zona.

La llegada de migrantes está forjando un cambio considerable con respecto al paisaje que conocíamos de los censos anteriores. Esto implicaría un impacto cultural que, como es obvio, no se puede discernir en detalle a través de un censo, aunque sí podemos ir viendo algunos elementos como las vías de inserción que los recién llegados tenían a su disposición. En cuanto a las actividades profesionales, cuando las mujeres se ganaban la vida, fueran nativas o extranjeras, era básicamente desempeñándose en tareas domésticas, excepto si por la ausencia o muerte del marido se encontraban al frente de una explotación o comercio. El origen no era un factor que modificara el tipo de ocupaciones para ellas, aunque algunas tenían más posibilidades de necesitar ganarse la vida (solteras y viudas más que casadas, argentinas y españo-

\footnotetext{
72 Contente, 2015.

73 Contente y Barcos, 2016.
} 
las más frecuentemente, por ejemplo, que las francesas), la mayoría de ellas encontrarían la solución a sus necesidades en las tareas del hogar.

La población masculina ofrece más matices, la ganadería era predominante aunque la agricultura seguía teniendo un peso importante entre las ocupaciones de los habitantes, lo que ha cambiado con el tiempo es quienes la realizan. Mientras en la cría de animales los argentinos siguen siendo mayoritarios, acompañados progresivamente por los ingleses, los italianos van acaparando paulatinamente el cultivo de la tierra. Si bien buena parte de los migrantes europeos encontraban una ocupación en las tareas agrícolas, para muchos extranjeros, los más calificados, el oficio que traen de sus tierras es la clave para hacerse un lugar en San Vicente que, con su creciente población, requería sus habilidades. Esto lleva a que se agruparan la mayoría de ellos, artesanos y comerciantes, en la zona urbana y el ejido. Es precisamente en esas dos zonas donde se encuentran la mayoría de las casas de azotea y donde se concentraban una parte significativa de los migrantes italianos, franceses y españoles ${ }^{74}$, así como la mayoría de los sanvicentinos que sabían leer y escribir, y de los niños que iban a la escuela. Aunque también habían migrantes (artesanos o no) en la zona más puramente agrícola, el paisaje pueblerino contrastaría con el rural donde, salvo en algunos sectores, residían las familias en situaciones «poco decentes» como los mancebos del pago con sus hijos ilegítimos, y predominaban ampliamente las casas de paja, y la poca instrucción de los habitantes.

Sin duda este esquema se repetía en diversas escalas en el resto del país, llevando a consolidar el viejo y arraigado prejuicio, aún vigente en la Argentina contemporánea que pretende la superioridad de la ciudad sobre la campaña, de la población extranjera sobre la nativa.

74 No así los ingleses ubicados exclusivamente en zonas rurales y dedicándose solo a actividades relacionadas con la ganadería: ninguno de ellos declara otro tipo de ocupación. 
ANeXo:

1. San Vicente 1869. Distribución de la población en los diferentes CUARTELES

\begin{tabular}{|l|c|c|c|c|c|c|c|c|c|c|c|c|}
\cline { 2 - 15 } \multicolumn{1}{c|}{} & \multicolumn{2}{c|}{ Pueblo } & \multicolumn{2}{c|}{ Ejido } & \multicolumn{2}{c|}{ Cuartel 2 } & \multicolumn{2}{c|}{ Cuartel 3 } & \multicolumn{2}{c|}{ Cuartel 4 } & \multicolumn{2}{c|}{ Cuartel 5 } \\
\cline { 2 - 15 } \multicolumn{1}{c|}{} & cant & $\mathbf{\%}$ & cant & \% & cant & \% & cant & \% & cant & \% & cant & \% \\
\hline Arg & 345 & 60,3 & 387 & 72 & 738 & 76,5 & 544 & 73,3 & 463 & 75,2 & 720 & 88,1 \\
\hline It & 110 & 19,2 & 63 & 11,7 & 107 & 11,1 & 19 & 2,6 & 93 & 15,1 & 17 & 2,1 \\
\hline Fr & 48 & 8,4 & 32 & 6 & 57 & 5,9 & 38 & 5,1 & 8 & 1,3 & 21 & 2,6 \\
\hline Esp & 54 & 9,4 & 24 & 4,5 & 31 & 3,2 & 42 & 5,7 & 27 & 4,4 & 17 & 2,1 \\
\hline Or & 6 & 1 & 7 & 1,3 & 8 & 0,8 & 21 & 2,8 & 8 & 1,3 & 1 & 0,1 \\
\hline Ang & 3 & 0,5 & 4 & 0,7 & 10 & 1 & 41 & 5,5 & 10 & 1,6 & 33 & 4 \\
\hline Otr & 6 & 1 & 20 & 3,7 & 14 & 1,4 & 37 & 5 & 7 & 1,1 & 8 & 1 \\
\hline Ttl & 572 & 100 & 537 & 100 & 965 & 100 & 742 & 100 & 616 & 100 & 817 & 100 \\
\hline
\end{tabular}

\section{SAN Vicente 1869. DistribuCión de los habitantes SEGÚN NACIONALIDAD Y CUARTELES}

\begin{tabular}{|l|c|c|c|c|c|c|c|c|c|}
\cline { 2 - 10 } \multicolumn{1}{c|}{} & Arg & Ital. & Franc. & Españ & Orient. & Anglof. & otros & Tt extrj & Tt pobl* \\
\hline Ctl 2 & 738 & 107 & 57 & 31 & 8 & 10 & 14 & 227 & 965 \\
\hline Ctl 3 & 544 & 19 & 38 & 42 & 21 & 41 & 37 & 198 & 742 \\
\hline Ctl 4 & 463 & 93 & 8 & 27 & 8 & 10 & 7 & 153 & 616 \\
\hline Ctl 5 & 720 & 17 & 21 & 17 & 1 & 33 & 8 & 97 & 817 \\
\hline Tt rural & 2.465 & 236 & 124 & 117 & 38 & 94 & 66 & 675 & 3.140 \\
\hline$\%$ & 78,4 & 7,5 & 3,9 & 3,7 & 1,2 & 3 & 2,1 & 21,5 & $100 \%$ \\
\hline
\end{tabular}

\begin{tabular}{|l|c|c|c|c|c|c|c|c|c|}
\hline Ejido & 387 & 63 & 32 & 24 & 7 & 4 & 20 & 150 & 537 \\
\hline$\%$ & 72,1 & 11,7 & 5,6 & 4,5 & 1,3 & 0,7 & 3,7 & 27,9 & $100 \%$ \\
\hline
\end{tabular}

\begin{tabular}{|l|c|c|c|c|c|c|c|c|c|}
\hline Pueblo & 345 & 110 & 48 & 54 & 6 & 3 & 6 & 227 & 572 \\
\hline$\%$ & 60,3 & 19,2 & 8,4 & 9,4 & 1 & 0,5 & 1 & 39,7 & $100 \%$ \\
\hline
\end{tabular}

\begin{tabular}{|l|l|l|l|l|l|l|l|l|l|}
\hline Total & 3.197 & 409 & 204 & 195 & 51 & 101 & 92 & 1.052 & 4.249 \\
\hline
\end{tabular}

* Tt pobl, total población: suma de argentinos y total de extranjeros. 


\section{San Vicente 1869. Distribución de los habitantes SEGÚN NACIONALIDAD Y CUARTELES EN PORCENTAJES}

\begin{tabular}{|l|c|c|c|c|c|c|c|c|c|}
\cline { 2 - 10 } \multicolumn{1}{c|}{} & Arg & Ital & Franc & Españ & Orient. & Anglof. & otros & Tt extrj & Total $^{*}$ \\
\hline Ctl 2 & 76,5 & 11,1 & 5,9 & 3,2 & 0,8 & 1 & 1,4 & 23,4 & 100 \\
\hline Ct1 3 & 73,3 & 2,6 & 5,1 & 5,6 & 2,8 & 5,5 & 5 & 26,6 & 100 \\
\hline Ctl 4 & 75,2 & 15,1 & 1,3 & 4,4 & 1,3 & 1,6 & 1,1 & 24,8 & 100 \\
\hline Ctl 5 & 88,1 & 2,1 & 2,6 & 2,1 & 0,1 & 4 & 1 & 11,9 & 100 \\
\hline Tt rural & 2.465 & 236 & 124 & 117 & 38 & 94 & 66 & 675 & 3.140 \\
\hline$\%$ & 77,1 & 9,6 & 5 & 4,7 & 1,5 & 3,8 & 2,7 & 27,4 & 100 \\
\hline
\end{tabular}

\begin{tabular}{|l|c|c|c|c|c|c|c|c|c|}
\hline Ejido & 387 & 63 & 32 & 24 & 7 & 4 & 20 & 150 & 537 \\
\hline$\%$ & 72,1 & 11,7 & 5,6 & 4,5 & 1,3 & 0,7 & 3,7 & 27,9 & 100 \\
\hline
\end{tabular}

\begin{tabular}{|l|c|c|c|c|c|c|c|c|c|}
\hline Pueblo & 345 & 110 & 48 & 54 & 6 & 3 & 6 & 227 & 572 \\
\hline$\%$ & 60,3 & 19,2 & 8,4 & 9,4 & 1 & 0,5 & 1 & 39,7 & 100 \\
\hline
\end{tabular}

\begin{tabular}{|l|l|l|l|l|l|l|l|l|l|}
\hline Total & 3.197 & 409 & 204 & 195 & 51 & 101 & 92 & 1.052 & 4.249 \\
\hline
\end{tabular}

* Total: suma de argentinos y total de extranjeros.

\section{BIBLIOGRAFÍA}

Amaral, Samuel, "Trabajo y trabajadores rurales en Buenos Aires a fines del siglo XVIII", Anuario del IEHS, 2 (Tandil, 1987): 33-41.

Banzato, Guillermo, La expansión de la frontera bonaerense. Posesión y propiedad de la tierra en Chascomús, Ranchos y Monte. 1780-1880, Bernal, Universidad Nacional de Quilmes, 2005.

Banzato, Guillermo y Lanteri, Sol, "Forjando la frontera. Políticas públicas y estrategias privadas en el Río de la Plata, 1780-1860", Historia Agraria, 43 (La Plata, 2007): 435-458.

Barcos, M. Fernanda, Pueblos y ejidos de la campaña bonaerense. Una historia sociojurídica de los derechos de propiedad y la conformación de un partido: Mercedes, 1780-1870, Rosario, Prohistoria, 2013.

Cacopardo, M. Cristina, "La inmigración temprana italiana en un área rural de Buenos Aires: familia y trabajo en Luján en 1869”, Cuadernos de Trabajo, 2 (Luján, 1997): 10-61.

Cacopardo, M. Cristina, Extranjeras en la Argentina y argentinas en el extranjero. La visibilidad de las mujeres migrantes, Buenos Aires, Biblos, 2011. 
Cacopardo, María Cristina y Moreno, José Luis, La familia italiana y meridional en la emigración a la Argentina, Napoli, Ed. Scientifiche Italiane, 1995.

Cacopardo, María Cristina y Moreno, José Luis, “Cuando los hombres estaban ausentes: la familia del interior de la Argentina decimonónica", Hernán Otero y G. Velázquez, Poblaciones Argentinas. Estudios de demografía diferencial, Tandil, Propiep-Unicen, 1997: 13-28.

Ceva, Mariela: "El ciclo de la inmigración”, Hernán Otero (dir.), Historia de la Provincia de Buenos Aires. Tomo 1: Población, ambiente y territorio, Buenos Aires, Unipe/Edhasa, 2012: 309-336.

Chayanov, Alexander V., La organización de la unidad económica campesina, Buenos Aires, Nueva Visión, 1974.

Chiaramonte, J. C., Ciudades, provincias, Estados: orígenes de la Nación Argentina (1800-1846), Buenos Aires, Biblioteca del Pensamiento Argentino, Ariel Historia, 1997.

Contente, Claudia, "Percevoir l'invisible: le travail des femmes à la campagne de Buenos Aires du XIXème siècle à partir du recensement de 1869", Marrie-Pierre Arrizabalaga, Ioan Bolovan, Marius Eppel, Jan Kok y Mary Louise Nagata (coords.), Many Paths to Happiness? Studies in Population and Family History. A Festschrift for Antoinette Fauve-Chamoux, Amsterdam, Aksant Publishers, 2010: 81-95.

Contente, Claudia, "Some considerations about the marriage market for migrants in Almirante Brown (Buenos Aires, Argentina) at the end of the nineteenth century", Daniela Mârza, Luminița Dumănescu y Marius Eppel (eds.), Marriage through History, New Castle Upon Tyne, Cambridge Scholar Publishing, 2014: 451-467.

Contente, Claudia, Familias en la tormenta. Tierra, familia y trasmisión de patrimonio en el Río de la Plata, siglos XVIII y XIX, Buenos Aires, Prometeo, 2015.

Contente, Claudia y Barcos, María Fernanda, "La parte sumergida del iceberg. Mujeres trabajadoras en la campaña de Buenos Aires (Argentina) según el Primer Censo Nacional de Población de 1869", M. Teresa Ortega López (ed.), Jornaleras, Campesinas y Agricultoras. La Historia Agraria desde una perspectiva de género, Zaragoza, Prensas Universitarias de Zaragoza, 2015: 81-109.

Contente, Claudia y Barcos, María Fernanda, "Un mundo rural en transición. Población, actividades y migraciones en la campaña de Buenos Aires según el Primer Censo Nacional de Población de la República Argentina (1869)", Quinto Sol, 20/1 (La Pampa, 2016): 1-32, doi: http://dx.doi.org/10.19137/qs0865.

Devoto, Fernando y Rosoli, G., La inmigración italiana en la Argentina, Buenos Aires, Biblos, 1985.

Dubert, Isidro, "Vejez, familia y reproducción social en España, siglos XVIII-XX", Revista de Demografía Histórica, XXVII/II (Zaragoza: 2008): 87-122. 
Epifanio, Haydée, San Vicente, un pueblo, un partido (1780-1928), San Vicente, Municipalidad de San Vicente, 2001.

Fradkin, Raúl "Estancieros, hacendados o terratenientes? La formación de la clase terrateniente porteña y el uso de las categorías históricas y analíticas, Buenos Aires, 1750-1850", Marta Bonaudo y Alfredo Pucciarelli, La Problemática agraria. Nuevas aproximaciones, Buenos Aires, CEAL, vol. I, 1993: 17-59.

Furet, F. y Ozouf, J., Lire et écrire. L'alphabétisation des français de Calvin à Jules Ferry, París, Les éditions de Minuit, 1977.

Garavaglia, Juan Carlos, “Existieron los gauchos?”, Anuario del IEHS, 2 (Tandil, 1987): 42-52.

Garavaglia, Juan Carlos, Construir el Estado e inventar la Nación. El Río de la Plata, siglos XVIII-XIX, Buenos Aires, Prometeo, 2007.

Garavaglia, Juan Carlos, San Antonio de Areco, 1680-1880. Un pueblo de la campaña, del Antiguo Régimen a la modernidad argentina, Rosario, Prohistoria Ediciones, 2009.

García González, Francisco, "Las estructuras familiares y su relación con los recursos humanos y económicos”, Francisco Chacón y Joan Bertard, Familias. Historia de la sociedad española (del final de la Edad Media a nuestros días), Madrid, Ediciones Cátedra, 2011: 159-254.

Gelman, Jorge, “¿Gauchos o campesinos?” Anuario del IEHS, 2 (Tandil, 1987): 53-59.

Gelman, Jorge y Barsky, O., Historia del agro argentino. Desde la Conquista hasta fines del siglo XX, Buenos Aires, Grijalbo, 2001.

Gelman, Jorge y Santilli, Daniel, “¿Cómo explicar la creciente desigualdad? La propiedad de la tierra en Buenos Aires entre 1839 y 1867", Jorge Gelman (comp.), El mapa de la desigualdad en la Argentina, del siglo XIX, Rosario, Prohistoria, 2011: 171-218.

Gelman, Jorge y Santilli, Daniel, "Movilidad social y desigualdad en el Buenos Aires del siglo XIX: El acceso a la propiedad de la tierra entre el rosismo y el orden liberal", Hispanic American Historical Review, 93/4 (Durham NC, 2013): 659-684.

Gelman, Jorge y Santilli, Daniel, "Los salarios y la desigualdad en Buenos Aires, 1810-1870", América Latina en la Historia Económica, 21/3 (México, 2014): 83115.

Gelman, Jorge y Santilli, Daniel, "Salarios y precios de los factores en Buenos Aires, 1770-1880. Una aproximación a la distribución funcional del ingreso", Revista de Historia Económica-Journal of Iberian and Latin American Economic History, 33/1 (Cambridge, 2015): 153-186, doi: https://doi.org/10.1017/S0212610915000075.

GIHRR [Grupo de investigación en Historia Rural Rioplatense], "La sociedad rural bonaerense a principios del siglo XIX. Un análisis a partir de las categorías ocu- 
pacionales", Raúl O. Fradkin y J. C. Garavaglia (eds.), En busca de un tiempo perdido. La economía de Buenos Aires en el país de la abundancia 1750-1865, Buenos Aires, Prometeo, 2004: 21-63.

Goody, Jack, La raison graphique: la domestication de la pensée sauvage, Paris, Minuit, 1979.

Goody, Jack, Pouvoirs et savoirs de l'écrit, Paris, La dispute, 2007.

Hora, Roy, Historia económica de la Argentina en el siglo XIX, Buenos Aires, Siglo Veintiuno Editores, 2010.

Hora, Roy, "La evolución de sector agroexportador argentino en el largo plazo, 18802010”, Historia Agraria, 58 (La Plata, 2012): 145-181.

Levene, Ricardo, Historia de la Provincia de Buenos Aires y de la formación de sus pueblos, 2 vols., La Plata, Publicaciones del Archivo Histórico de la Provincia de Buenos Aires, 1941.

Massé, Gladys, "El tamaño y el crecimiento de la población desde la Conquista hasta 1870", Hernán Otero (dir.), Historia de la Provincia de Buenos Aires. Tomo 1: Población, ambiente y territorio, Buenos Aires, UNIPE-EDHASA, 2012: 143-156.

Mateo, José, "La sociedad: población, estructura social y migraciones", Historia de la Provincia de Buenos Aires, Tomo III, Marcela Ternavasio (dir.), De la Organización provincial a la federalización de Buenos Aires (1821-1880), Buenos Aires, Unipe/Edhasa, 2013: 73-116.

Mayo, Carlos, "Sobre peones y malentretenidos: el dilema de la economía rural rioplantense durante la época colonial", Anuario del IEHS, 2 (Tandil, 1987): 25-32 y $60-70$.

Míguez, Eduardo, Historia económica de la Argentina desde la Conquista a la crisis de 1930, Buenos Aires, Sudamericana, 2008.

Míguez, Eduardo, Argeri, María Elena, Bjerg, María y Otero, Hernán, "Hasta que la Argentina nos una: reconsiderando las pautas matrimoniales de los inmigrantes, el crisol de razas y el pluralismo cultural", Hispanic American Historical Review, 71/4 (Durham NC, 1991): 782-808.

Moreno, José Luis, "Sexo, matrimonio y familia: la ilegitimidad en la frontera pampeana del Río de la Plata, 1750-1850", Boletín del Instituto de Historia Argentina y Americana Dr. Emilio Ravignani 3/16-17 (Buenos Aires, 1998): 61-84.

Moya, José, Cousins and strangers. Spanish inmigrants in Buenos Aires, 1850-1930, California, University of California Press, 1998.

Moya, José, "Mujer, moral y trabajo en la emigración española a la Argentina", Amancio Liñares Giraut (coord.), El protagonismo de la mujer en las corrientes migratorias españolas, Vigo, Grupo España Editor, 2009: 101-122. 
Ortelli, Sara, "La frontera y el mundo indígena pampeano (1516-1820)", Raúl Fradkin (dir.), Historia de la Provincia de Buenos Aires, Tomo II, Buenos Aires de la conquista hasta 1820, Buenos Aires, Unipe/Edhasa, 2012: 155-177.

Otero, Hernán, "Redes sociales primarias. Movilidad especial e inserción social de los inmigrantes en la Argentina. Los franceses de Tandil, 1850, 1914”, María Bjerg y Hernán Otero, Inmigración y redes sociales en la Argentina Moderna, Tandil, CEMLA-IEHS, 1995: 81-105.

Otero, Hernán, "Estadística censal y construcción de la Nación. El caso argentino, 1869-1914”, Boletín del Instituto de Historia Argentina y Americana Dr. Emilio Ravignani, 3/16-17 (Buenos Aires, 1998): 123-149.

Otero, Hernán, Estadística y Nación. Una historia conceptual del pensamiento censal de la Argentina Moderna. 1869-1914, Buenos Aires, Prometeo Libros, 2006.

Otero, Hernán y Pellegrino, Adela, “Compartir la ciudad. Patrones de residencia e integración de inmigrantes en Buenos Aires y Montevideo durante la inmigración masiva", Hernán Otero (dir.), El mosaico argentino, Buenos Aires, Siglo XXI de Argentina editores, 2004: 19-69.

Primer Censo de la República Argentina, verificado los días 15, 16 y 17 de septiembre de 1869, bajo la dirección de Diego G. De la Fuente, superintendente del Censo, Buenos Aires, Imprenta del Porvenir, 1872.

Ratto, Silvia, La frontera bonarense (1810-1828): espacio de conflicto, negociación y convivencia, La Plata, Publicaciones del Archivo Histórico de la Provincia de Buenos Aires, Estudios sobre la Historia y Geografía Histórica de la Provincia de Buenos Aires, 2003.

Ratto, Silvia, "La frontera y el mundo indígena", Historia de la Provincia de Buenos Aires, Tomo II, Marcela Ternavasio (dir.), De la Organización provincial a la federalización de Buenos Aires (1821-1880), Buenos Aires, Unipe/Edhasa, 2013: 247-268.

Ratto, Silvia y Santilli, Daniel, "De factoría a poblado agropecuario. La evolución del partido de Bahía Blanca hacia 1869", Cuadernos del Sur, 33 (Bahía Blanca, 2004): 47-78.

Registro Estadístico de la Provincia de Buenos Aires, Buenos Aires, Publicación Oficial, 1869.

Sabato, Hilda, Capitalismo y ganadería en Buenos Aires: la fiebre del lanar 18501890, Buenos Aires, Sudamericana, 1989.

Fecha de recepción: 26 de marzo de 2014.

Envía texto modificado: 6 de marzo de 2015.

Fecha de aceptación: 16 de marzo de 2015. 


\section{From figures to people. The population of San Vicente (Buenos Aires) according to Argentina's First National Census (1869)}

Census data from the First National Census (1869) of Saint Vincent Partido (Buenos Aires) will allow us to address a number of aspects regarding the population, such as productive activities and their development from the early nineteenth century onwards. These aspects will be analysed by parameter, including place of residence (rural or urban), gender and birth place. Beyond purely quantitative aspects, levels of illegitimacy and literacy, type of dwelling and areas of residence will also allow us to understand what lies beneath certain present-day cultural issues, thereby providing a better picture of this rural area at the time when immigrants began to enter the country en masse.

KEY-WORDS: Rural history; countryside of Buenos Aires; census; migration; nineteenth century. 